\title{
Randphänomene in der mittelalterlichen Kultur
}

\author{
Michael Stolz
}

\begin{abstract}
This article explores phenomena of marginality in different areas of medieval culture. The introduction explains medieval concepts of the "margin". In the first part, the author analyzes the tension between the "centre" and the "margin" as found in medieval conceptions of the world such as labyrinths and the mappae mundi. Secondly, he examines the interdependency of social and textual marginalization as it occurs in the 14th century Hausbuch of Michael de Leone. The third part of the article is dedicated to the Munich manuscript of Wolframs von Eschenbach Titurel, a text situated on the margins of the famous Parzival-novel both in terms of its physical location and also its poetic thought. The survey of these examples shows that margins often refer to the centre of cultural constellations despite their allegedly subsidiary role.
\end{abstract}

Keywords: Labyrinth; mappae mundi; Michael de Leone; Titurel; Parzival

Welche Rolle spielen Randphänomene in wissenschaftlichen Disziplinen, die sich mit dem Mittelalter befassen? - Diese Frage kann sich auf die Erforschung zeitlicher, räumlicher oder auch fachspezifischer Phänomene beziehen. Denkbar ist, dass man der notorischen Frage nachgeht, wann das Mittelalter beginnt und wann es endet. Man könnte geographische Aspekte ins Spiel bringen und ergründen, in welchen kulturellen Räumen überhaupt sinnvoll von einem „Mittelalter“ gesprochen werden kann - in den verschiedenen Kulturen differieren die Mittelalter-Begriffe bekanntermaßen erheblich. Man könnte aber auch die Eigenarten einer zunehmend interdisziplinär ausgerichteten Mittelalterforschung in den Blick nehmen: Wo gelangen die einzelnen Fächer an ihre Ränder und Grenzen? Wo überschneiden sie sich und wo führen sie - gerade in der wechselseitigen Überlappung und Vernetzung - zu neuen Einsichten und Erkenntnissen?

Fragen dieser Art sollen in dem vorliegenden Beitrag angegangen werden, auch wenn sie darin weder erschöpfend noch endgültig beantwortet werden können. Die Randphänomene, von denen zu handeln ist, sollen in konkreten Quellen der mittelalterlichen Kultur aufgesucht werden. Dort begegnen Aspekte des Randständigen, des Marginalen, aber auch des Übergangs, der Zone, der unfesten Grenze. Zwei grundlegende Beobachtungen sollen dabei vorweggenommen werden - sie lassen sich auf Strukturen in ganz unterschiedlichen kulturellen Erscheinungen beziehen.

Zum einen: Erst durch die Ränder lässt sich eine Mitte bestimmen, erst sie schaffen den Begriff eines Zentrums. Ränder sind also - wie das Zentrum selbst - gemacht; sie sind das Produkt von normierender Setzung und von deren Wahrnehmung; sie geben damit auch Aufschluss über die Kultur, aus der sie hervorgegangen sind. Zum anderen: Ränder sind - auch in vermeintlich stabilen Ordnungen - niemals fest. Als Resultate kulturell vorgeprägter Vermessungen und Grenzziehungen sind sie prinzipiell beweglich, hinterfragbar und von beschränkter Geltungsdauer.

Blickt man mit Vorüberlegungen dieser Art auf den Objektbereich der mittelalterlichen Kultur, so wird man dort auf der Suche nach einer begrifflichen Orientierung zunächst 
enttäuscht. Denn aussagekräftige lexematische Belege für das Phänomen des Randes, des Marginalen sind nicht eben häufig:

Mit der lateinischen Bezeichnung margo begegnet der „Rand“ als lokale Determination etwa in den ,Etymologiae“ des spanischen Bischofs Isidor von Sevilla, jener um 600 angefertigten Enzyklopädie, die antikes Wissen für christliche Zwecke, konkret für das Bibelstudium, aufbereitet. In einem Abschnitt, der verschiedene geographische Bezeichnungen abhandelt, erscheint auch das Wort margo, das Isidor als Randanteil eines beliebigen Raumes (pars cuiuslibet loci) definiert. ${ }^{1}$ Als Beispiel nennt er das Meer, von dessen lateinischem Namen mare er das Wort margo abgeleitet sehen will. Dieses pseudo-etymologische Verfahren ist charakteristisch für Isidors Methode. Der Verfasser der ,Etymologiae“ versucht, eine christlich geprägte Wahrheit im Ursprung der Wörter aufzusuchen, was immer wieder zu gewagten Wortdeutungen führt.

Eine andere Belegstelle liefert ein unter dem Namen des karolingischen Gelehrten Hrabanus Maurus überlieferter Kommentar zum alttestamentlichen Buch Ezechiel. Der Verfasser bezieht sich auf die dort enthaltene Tempelbeschreibung, genauer auf das Maß eines vor den Schlafkammern der Wächter befindlichen umzäunten Gebiets oder einer Eingangszone: Et [mensus est] marginem ante thalamos cubiti unius („Und der Rand vor den Gemächern maß eine Elle," nach Ezechiel 40, 12). Er legt diese Zone auf den Glauben (fides) aus, welcher den guten Werken (bona opera bzw. perfecta operatio) und der Andacht (contemplatio) vorausgeht. ${ }^{2}$

Neben dem Wort margo ließe sich als mittelalterliche Bezeichnung für den Rand der Begriff limbus - mit der ursprünglichen Bedeutung von „Saum“ oder „Bordüre“ - nennen. Er bezeichnet in der mittelalterlichen Theologie den Aufenthaltsort jener Gerechten, die nach der damaligen Auffassung nicht in den Himmel gelangen konnten: Es handelt sich um die alttestamentlichen Väter und die ungetauften Kinder, die ihr Dasein nach dem Tod in einer Art Vorhof der Hölle fristen (limbus patrum - limbus puerorum). ${ }^{3}$

Die erwähnten Begriffe bieten nicht mehr als einen schlaglichtartigen Ausschnitt dessen, was mittelalterliche Menschen, insbesondere Theologen, unter „Rändern“ in geogra-

1 Isidori Hispalensis episcopi Etymologiarum sive originum libri XX. Hrsg. v. Wallace M. Lindsay (Scriptorum classicorum bibliotheca Oxoniensis). 2 Bde. Oxford 1911, Bd. 2, XIV, 8, 42. Vgl. zu Isidor stellvertretend (mit weiterer Literatur): Michael Stolz, Artes-liberales-Zyklen. Formationen des Wissens im Mittelalter (Bibliotheca Germanica 47). 2 Bde. Tübingen, Basel 2004, Bd. 1, S. 16 - 19; Peter Kuhlmann, Theologie und historische Semantik. Historisierung von Wissen in Isidors von Sevilla ,Etymologiae". Millennium 3 (2006), S. 143-157.

2 Beati Rabani Mauri Fuldensis Abbatis et Moguntini Archiepiscopi Commentariorum in Ezechielem libri viginti. Hrsg. v. Jacques-Paul Migne (PL 110). Paris 1852, Sp. 493-1084, hier Sp. 906B, 908C-910B. Vgl. zu Hrabanus Maurus Raymund Kottje u. Harald Zimmermann (Hgg.), Hrabanus Maurus. Lehrer, Abt und Bischof (Abhandlungen der geistes- und sozialwissenschaftlichen Klasse. Einzelveröffentlichung 4). Mainz 1982. - Ähnlich ein Hrabanus Maurus zugeschriebenes biblisches Wörterbuch, das wohl aus dem 12. Jahrhundert stammt: Allegoriae in universam sacram scripturam. Hrsg. v. Jacques-Paul Migne (PL 112). Paris 1852, Sp. 849-1088, hier Sp. 995C: Margo est fides, ut in Ezechiele: „Et marginem ante thalamum " id est, fidem ante contemplationem. Als möglicher Verfasser kommt Garnier de Rochefort in Frage; vgl. Ludwig Hödl, Garnerius [...] v. Rochefort. In: Lexikon des Mittelalters. Bd. 4 (1989), Sp. 1119.

3 Belege liefert beispielsweise Ludwig Schütz, Thomas-Lexikon. Sammlung, Übersetzung und Erklärung der in sämtlichen Werken des h. Thomas von Aquin vorkommenden Kunstausdrücke und wissenschaftliche Aussprüche. 2., sehr vergrösserte Aufl. Paderborn 1895 (Faksimile-Neudruck Stuttgart 1958), S. 447. 
phischer, lokaler, aber auch katechetischer Hinsicht verstanden haben mögen. Der Einblick bleibt selektiv und lässt es geraten erscheinen, Randphänomenen des Mittelalters nicht nur in lexematischen Belegen, sondern vielmehr in den Ordnungs- und Kompositionsverfahren konkreter Quellenbefunde nachzuspüren. Die folgenden Betrachtungen versuchen, dies im Blick auf ausgewählte Text- und Bildzeugnisse des europäischen, insbesondere des deutschsprachigen Mittelalters zu leisten. Behandelt werden Erscheinungsformen des Randes in Weltmodellen wie dem Labyrinth und den mappae mundi, in Verfahren der sozialen und textuellen Marginalisierung sowie in literarischen Gestaltungsweisen einer gleichermaßen poetologisch fundierten wie überlieferungsgeschichtlich dokumentierten Anlagerung von Texten. Den zu untersuchenden Objektbereichen gemeinsam ist die Tatsache, dass vermeintlich Randständiges geeignet ist, auf das Zentrum kultureller Phänomene und Konstellationen $\mathrm{zu}$ verweisen. Insofern ermöglicht es die Betrachtung von Randphänomenen, Grenzen und Übergänge zu beschreiten, dabei aber auch das „Andere im Eigenen“ und das „Eigene im Anderen“ zu erkennen. ${ }^{4}$ Letztlich verweist die Beschäftigung mit Randphänomenen auf einen Grundzug mediävistischer Forschung. Diese sieht sich, von der eigenen Gegenwart herkommend, stets auf eine Spannung von „Alterität“ und „Modernität“ gegenüber der mittelalterlichen Kultur verwiesen. ${ }^{5}$

\section{Das Labyrinth der Welt}

Am Anfang des ersten eigenständigen Buches in deutscher Sprache, des ,Evangelienbuchs‘ Otfrids von Weißenburg aus der Zeit um 870/71, steht ein Labyrinth. In der heute in Wien aufbewahrten Handschrift (Österreichische Nationalbibliothek, Cod. 2687, Bl. Ir), an deren Herstellung der Weißenburger Mönch Otfrid selbst mitwirkte, eröffnet das Labyrinth den Zugang zu einer deutschsprachigen Nacherzählung und Ausdeutung des Lebens Jesu. ${ }^{6}$ Als

Zur Verwendung im vierten Gesang von Dantes ,Inferno‘: Dante Alighieri, La Divina Commedia. Inferno. Commento di Anna Maria Chiavacci Leonardi. Milano 1991, S. 103 f. Vgl. auch Leo Scheffczyk, Limbus. In: Lexikon für Theologie und Kirche. 3., völlig neu bearb. Aufl. Bd. 6 (1997), Sp. 936 f.

4 Formulierungen in Anlehnung an Jacques Derrida, Tympan. In: Marges de la philosophie. Paris 1972, S. I-XXV. Deutsch: Tympanon. In: Ders., Randgänge der Philosophie. Hrsg. v. Peter Engelmann. Aus dem Französischen von Gerhard Ahrens u. a. (Passagen Philosophie). 2., überarb. Aufl. Wien 1999, S. 13-29, hier S. 14. Nach Derrida besteht das Anliegen der Philosophie darin, ,ihr Anderes zu denken“, jenes des Philosophen darin, „sein Anderes zu denken: sein eigenes Anderes, das Eigene seines Anderen, ein anderes Eigenes“ (ebd.).

5 Vgl. stellvertretend Paul Zumthor, Essai de poétique médiévale. Paris 1972. Avec une préface de Michel Zink et un texte inédit de Paul Zumthor. 2. Aufl. Paris 2000; Hans Robert Jauss, Alterität und Modernität der mittelalterlichen Literatur. Gesammelte Aufsätze 1956-1976. München 1977, bes. S. 9-49; Christian Kiening, Alterität und Methode. Begründungsmöglichkeiten fachlicher Identität. In: Peter Strohschneider (Hg.), Germanistische Mediävistik und „Bologna-Prozess“ (Mitteilungen des Deutschen Germanistenverbandes 52, Heft 1). Bielefeld 2005, S. 150-166 (mit weiterer Literatur S. 151, Anm. 2).

6 Vgl. Otfrid von Weißenburg, Evangelienharmonie. Vollständige Faksimile-Ausgabe des Codex Vindobonensis 2687 der Österreichischen Nationalbibliothek. Einführung von Hans Butzmann (Codices selecti phototypice impressi 30). Graz 1972; Otfrid von Weißenburg, Evangelienbuch. Hrsg. v. Wolfgang Kleiber u. Ernst Hellgardt. Bd. 1: Edition nach dem Wiener Codex 2687. Hrsg. u. bearb. v. Wolfgang Kleiber unter Mitarb. v. Rita Heuser. Tübingen 2004. Bd. 2: Edition der Heidelberger Handschrift P (Codex Pal. Lat. 52) und der Handschrift D (Codex Discissus: Bonn, Berlin/Krakau, Wolfenbüttel). Hrsg. u. bearb. v. Wolfgang Kleiber unter Mitarb. v. Rita Heuser. 2 Tle. Tübingen 2006. Diese handschriftengetreue Ausgabe übernimmt die Blattangaben der Textzeugen und verzichtet auf eine moderne Seitenzählung. For- 
Evangelienharmonie bietet der Text eine Synthese der vier neutestamentlichen Evangelien. Die Anlage des Labyrinths birgt eine Spannung von Rand und Zentrum, sind die den Mittelpunkt kreisförmig einschließenden Umgänge doch gleichermaßen von diesem entfernt wie auf ihn hin orientiert.

In seiner Form geht das Labyrinth auf antike Vorstellungen zurück, besonders jene, die im Zusammenhang mit dem Theseus-Mythos entwickelt wurden. ${ }^{7}$ Dem Mittelalter stand diese Sage in der Version zur Verfügung, die Ovid und Vergil sowie spätantike Autoren wie der Mythograph Fulgentius und der Vergil-Kommentator Servius hinterlassen hatten: ${ }^{8}$ Im Auftrag des kretischen Königs Minos erbaut der kunstfertige Daedalus ein Labyrinth, um darin den Stiermenschen Minotaurus einzuschließen, den Minos' Gattin Pasiphaë nach ehebrecherischer Verbindung mit einem Stier geboren hat. Die Athener sind diesem Ungeheuer zu einem regelmäßigen Tribut von Menschenopfern verpflichtet. Als der attische Königssohn Theseus als Opfer ausgelost wird, gelingt es diesem, den Minotaurus zu bezwingen. Unterstützt von Daedalus und der kretischen Königstochter Ariadne findet Theseus den Ausgang des Labyrinths mit Hilfe eines eingeschleusten Fadens wieder.

Die christlich-mittelalterliche Deutung dieses Mythos machte aus Minotaurus den Satan, aus dessen Klauen Theseus, eine Präfiguration des Erlösers Christus, „die Seele am Ariadne-Faden der göttlichen Gnade befreite.“ Das Labyrinth gerät auf diese Weise zum

schungsliteratur in Auswahl: Wolfgang Haubrichs, Ordo als Form. Strukturstudien zur Zahlenkomposition bei Otfrid von Weißenburg und in karolingischer Literatur (Hermaea NF 27). Tübingen 1969; ders., Die Anfänge. Versuche volkssprachiger Schriftlichkeit im frühen Mittelalter (ca. 700-1050/60) (Geschichte der deutschen Literatur von den Anfängen bis zum Beginn der Neuzeit 1, 1). 2., durchges. Aufl. Tübingen 1995, bes. S. 260-272, 292-312; Horst Dieter Schlosser, Zur Datierung von Otfrieds ,Evangelienbuch“. Zeitschrift für deutsches Altertum und deutsche Literatur 125 (1996), S. 386-391; Beate Kellner, Wort Gottes - Stimme des Menschen. Textstatus und Profile von Autorschaft in Otfrids von Weißenburg ,Evangelienbuch‘. In: Dies., Peter Strohschneider u. Franziska Wenzel (Hgg.), Geltung der Literatur. Formen ihrer Autorisierung und Legitimierung im Mittelalter (Philologische Studien und Quellen 190). Berlin 2005, S. 139-162; Nicola Zotz, Otfrid von Weißenburg, Evangelienbuch (863/871). In: Cornelia Herberichs u. Christian Kiening (Hgg.), Literarische Performativität. Lektüren vormoderner Texte (Medienwandel - Medienwechsel - Medienwissen 3). Zürich 2008, S. 45-61. Zur Labyrinthdarstellung Haubrichs, Ordo als Form, S. 283-293; Helmut Birkhan, Laborintus - labor intus. Zum Symbolwert des Labyrinths im Mittelalter. In: Herbert Mitscha-Märheim, Herwig Friesinger u. Helga Kerchler (Hgg.), Festschrift für Richard Pittioni zum siebzigsten Geburtstag. Bd. 2: Industriearchäologie und Metalltechnologie. Römerzeit, Frühgeschichte und Mittelalter, Sonstiges. Wien 1976, S. 423-454, hier S. 430 f.; Werner Batschelet-Massini, Labyrinthzeichnungen in Handschriften. Codices manuscripti 4 (1978), S. 33-65, hier Nr. A 1, S. 44/46, ferner S. 61; Wolfgang Haubrichs, Error inextricabilis. Form und Funktion der Labyrinthabbildung in mittelalterlichen Handschriften. In: Christel Meier u. Uwe Ruberg (Hgg.), Text und Bild. Aspekte des Zusammenwirkens zweier Künste in Mittelalter und früher Neuzeit. Wiesbaden 1980, S. 63-174, hier Nr. 9, S. 78, ferner S. 146, 150-158; Hermann Kern, Labyrinthe. Erscheinungsformen und Deutungen. 5000 Jahre Gegenwart eines Urbilds. 4., unveränd. Aufl. München 1999, S. 140 f., u. Nr. 172, S. 148 (mit weiterer Literatur).

7 Vgl. Kern (Anm. 6), S. 43-67. Labyrinthische Modelle im Kulturvergleich behandelt neben Kern: Jan Pieper, Das Labyrinthische. Über die Idee des Verborgenen, Rätselhaften, Schwierigen in der Geschichte der Architektur (Schriften des Deutschen Architekturmuseums Frankfurt am Main). Braunschweig, Wiesbaden 1987 (ND Basel, Boston, Berlin 2009; Bauwelt Fundamente 127).

8 Vgl. Karl Kerényi, Labyrinth-Studien. Labyrinthos als Linienreflex einer mythologischen Idee (Albae Vigiliae NF 10). 2., erw. Ausg. Zürich 1950, bes. S. 31-34; sowie die unter Anm. 6 genannten Arbeiten von Haubrichs, Ordo als Form, S. 289; Birkhan, S. 434; Haubrichs, Error inextricabilis, S. 113-119; Kern, S. 212 f. 

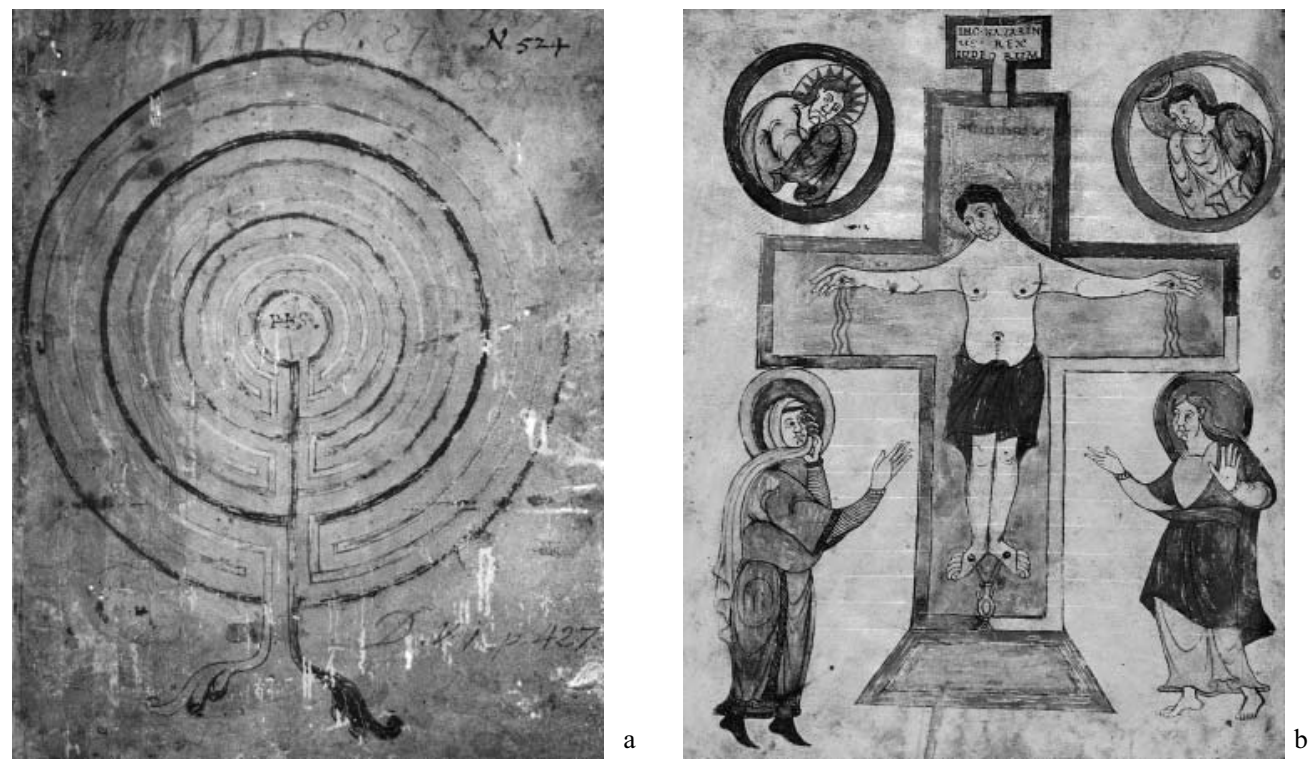

Abb. 1 a/b: Otfrid von Weißenburg, ,Evangelienbuch', Handschrift Wien, Österreichische Nationalbibliothek, Cod. 2687, Bl. Ir und 153v - Österreichische Nationalbibliothek, Wien

„Sinnbild des mundus peccatus,“ der „sündigen Welt.“9 Vorbereitet ist diese Anschauung bei Vergil, der das Labyrinth in der ,Aeneis' anlässlich der Unterwelt-Fahrt seines Helden erwähnt. Dem von Daedalus erbauten Gebäude, der domus Daedali, wird dabei „Mühsal“ (labor) und unentwirrbarer Irrgang (inextricabilis error) zugesprochen. ${ }^{10}$ In der christlichen Interpretation konnte daraus eine etymologische Deutung des Labyrinths als labor intus, als „Mühsal“ des ins „Innere“ der sündigen Welt verstrickten Christen werden. ${ }^{11}$

Das Labyrinth in Otfrids ,Evangelienbuch“ bringt exakt diese Haltung zum Ausdruck. Auf einem Vorsatzblatt des Codex dargestellt, soll es den Leser zur kontemplativen Andacht über die Sündenverfallenheit des Diesseits anhalten, die erst durch das Wirken Christi überwunden wird (vgl. Abb. 1a).

Der Sieg über den mundus peccatus manifestiert sich im Zeichen des Kreuzes, dem eine zweite in die Wiener Handschrift aufgenommene Abbildung gewidmet ist (B1. 153v). Sie zeigt den Kruzifixus umgeben von Symbolen der Sonne und des Mondes, beweint von Maria und Johannes, die in Klagegesten verharren. Am Beginn des fünften, des letzten Buches von Otfrids Evangelienharmonie, bezeichnet das Kreuz den mundus reparatus, die durch Christi Tod wiederhergestellte Weltordnung (vgl. Abb. 1b).

9 Zitate nach Haubrichs, Die Anfänge (Anm. 6), S. 304. Vgl. auch Haubrichs, Ordo als Form (Anm. 6), S. 289, zu den sog. ,Mythographi Vaticani'.

10 Vergil, Aeneis. Lateinisch-deutsch. In Zusammenarb. mit Maria Götte hrsg. u. übers. v. Johannes Götte. 5. Aufl. München 1980, Buch VI, Vers 27, S. 222.

11 Vgl. mit Nachweisen die unter Anm. 6 genannten Arbeiten von Birkhan, S. 436; Haubrichs, Error inextricabilis, S. 119-125. 
Die Darstellung ist mit ihren Farbtönen (Rotorange, Braun) auf jene des Labyrinths abgestimmt; die Maße sind so angelegt, dass sich Länge und Breite des Kreuzes in den äußersten Ring des Labyrinths einpassen. Zählt man die Umgänge des Labyrinths durch, so kommt man auf die Zahl Elf, die in der mittelalterlichen Zahlensymbolik für Frevel und Sünde steht. Die Elf überschreitet die Zahl Zehn, die vollkommene Zahl der Gebote, sie liegt unter der Zahl Zwölf, der Zahl der Apostel. ${ }^{12}$

Otfrid selbst spielt in seinem ,Evangelienbuch“ auf das „Labyrinth der Welt“ an, dies anlässlich der Darstellung von Christi Versuchung in der Wüste (II, 4, 5-14). ${ }^{13}$ Der Abschnitt trägt die lateinische Überschrift DUCTUS EST IHC IN DESERTUM. Der Ausdruck desertum (,Wüste") bezeichnet dabei in seiner wörtlichen Bedeutung jenen verlassenen, ja randständigen Ort, an dem sich Jesus aufhält, als er vom Satan versucht wird. Bei Otfrid reflektiert der Satan zu Beginn dieser Szene über die Verschlossenheit der labyrinthischen Welt, die er als Pförtner bewacht: „Er bedachte eine Zeit lang, dass er der Türhüter war“ (thaz er ther dúruuart uuáf), „er hatte den Eingang der Welt selbst versperrt“ - er ińgang therera uuóroltı · bifperrit félbo hab\&l (II, 4, $7 \mathrm{f}$.).

Der Eingang in diese Welt wird von dem Schließer Satan nur für jene geöffnet, die ihn mit dem Makel der Erbsünde betreten. Christus hingegen ist als Gottmensch ohne diese Sünde in die Welt gekommen. Dies macht den Satan misstrauisch, und er will Christus erproben. Mit der Szene des Pförtners, der das Labyrinth einer geschlossenen und heillosen Welt bewacht, motiviert Otfrid im Anschluss an zeitgenössische Theologen die Versuchung Christi in der Wüste.

Einen Ausweg aus jener Welt weist das Zeichen des Kreuzes. Die durch Christus bewirkte Erlösung rühmt Otfrid in einem Kreuzeshymnus am Beginn des fünften Buches: ${ }^{14}$ „Die Spitze des Kreuzes dort oben“ (Thes krúzef horn thar óbana) weist „gen Himmel“ (ın hímıla); die Arme und Hände des Gekreuzigten „zeigen auf die Enden der Welt“ (thıe zeigont uuóroltentı); der „mittlere Balken“ (mittılo bóum), der Christi Leib trug, weist auf den „Erdboden“ (uuóroltfloum) (V, 1, 19-21). Legt man das Kreuz aber „waagrecht“ (nídarhaldaz) hin, so „weist es dem Herrn auf allen vier Seiten ringsum her alles, den ganzen Erdkreis als Eigentum zu“ ( $z$ zeigot ímo $ı$ allaz/ fiar hálbun umbıríng · állan thefan uuóroltržng (V, 1, $31 \mathrm{f}$.).

Blickt man von diesen Sätzen aus zurück auf die Abbildungen der Wiener Handschrift, so wird deutlich, dass sich der Schnittpunkt der Kreuzesbalken mit dem Zentrum des kreisförmigen Labyrinths deckt. Der Ort des Minotaurus-Satan wird also genau durch die Längs- und Querbalken des Marterholzes Christi überwunden. Das in seinen Ausmaßen die Weltenden umspannende, über die Welt hinausweisende Kreuz trifft das Labyrinth des Satans in dessen Innerstem. Diesen Sachverhalt scheint ein Leser des 16. oder 17. Jahrhunderts dadurch festgehalten zu haben, dass er in den Mittelpunkt des Labyrinths das Wort Phas, wohl im Sinne von lateinisch fas, „göttliches Recht,“ schrieb. ${ }^{15}$

12 Vgl. die unter Anm. 6 genannten Arbeiten von Haubrichs, Ordo als Form, S. 293-297; Birkhan, S. 437; Kern, S. 140 f., 210.

13 Vgl. Otfrid von Weißenburg, Evangelienbuch. Bd. 1 (Anm. 6), Bl.45v/46r. Dazu Haubrichs, Ordo als Form (Anm. 6), S. 283 f.; ders., Error inextricabilis (Anm. 6), S. 150-152.

14 Vgl. Otfrid von Weißenburg, Evangelienbuch. Bd. 1 (Anm. 6), Bl. 154r-155r. Dazu Haubrichs, Error inextricabilis (Anm. 6), S. $157 \mathrm{f}$. 


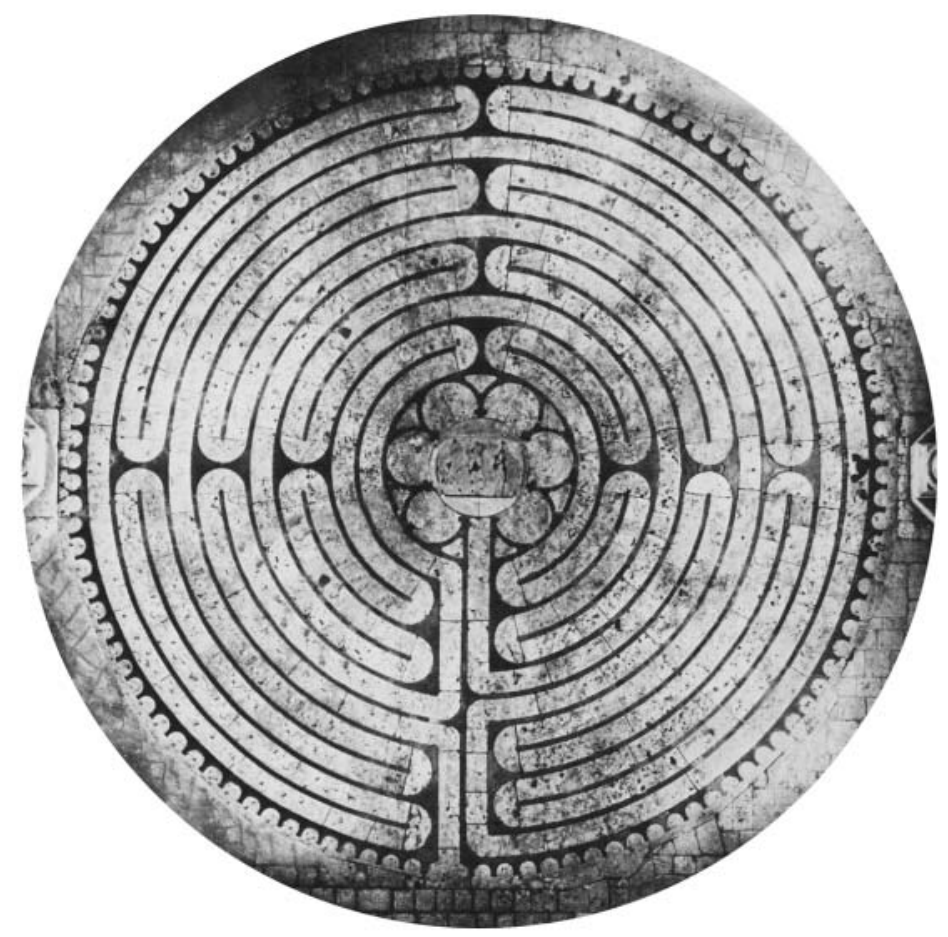

Abb. 2: Labyrinth der Kathedrale von Chartres - Carlheinz Heitmann, Prestel Verlag, München

Die Spannung von Rand und Zentrum, die in den mittelalterlichen Labyrinthdarstellungen vorliegt, zeigt sich noch deutlicher in einem späteren Typus, der besonders klar in einer Darstellung auf dem Fußboden der Kathedrale von Chartres aus der ersten Hälfte des 13. Jahrhunderts ausgeprägt ist (vgl. Abb. 2). ${ }^{16}$

Diesem Labyrinth ist das Zeichen des Kreuzes nun erkennbar eingeschrieben. Die wiederum elf Umgänge sind so angelegt, dass sich im Aufeinandertreffen ihrer Windungen eine Kreuzesform ergibt. Wer den Umgängen folgt, gerät dabei mitunter ganz nahe an den Mittelpunkt, ohne diesen zu erreichen. Erst der letzte Umgang, der die rechte äußerste Hemisphäre beschreitet, führt dem Mittelpunkt entgegen, der hier als sechsblättrige Blüte, vielleicht in Analogie zu einer Fensterrose, gestaltet ist. Auf diese Weise werden Rand und Zentrum in eine enge Beziehung gesetzt: Wer sich im äußeren Umgang dem Mittelpunkt am entferntesten glaubt, ist diesem doch ganz nahe.

15 Vgl. die unter Anm. 6 genannten Arbeiten von Birkhan, S. 439; Batschelet-Massini, S. 61; Haubrichs, Error inextricabilis, Nr. 9, S. 78; Kern, Nr. 172, S. 148.

16 Vgl. die unter Anm. 6 genannten Arbeiten von Haubrichs, Error inextricabilis, Nr. 6, S. 104; Kern, Labyrinthe, S. 141, u. Nr. 255-257, S. 225 f. (mit weiterer Literatur); sowie Brigitte Kurmann-Schwarz u. Peter Kurmann, Chartres. Die Kathedrale. Regensburg 2001, bes. S. 90 f., und Hans Jantzen, Kunst der Gotik. Klassische Kathedralen Frankreichs: Chartres, Reims, Amiens. Neuausgabe, 2. Aufl., erw. u. komm. durch ein Nachwort von Hans-Joachim Kunst. Berlin 2003, S. 79 f. 
Das Labyrinth von Chartres nimmt die gesamte Breite des Mittelschiffs der Kathedrale ein. Die mittelalterlichen Besucher, die das Marienheiligtum von Chartres als Pilger betraten, trafen vom Westportal aus, noch ehe sie sich dem Altar und den Reliquien näherten, auf das Labyrinth. Sie konnten das in den Boden eingelassene Plattenmuster als Aufforderung verstehen, sich über die mäanderartigen Linien hin auf das Zentrum zuzubewegen. Am Beispiel von Chartres wird deutlich, dass die mittelalterlichen Labyrinthe wie auch das Kirchenschiff „orientiert“, d. h. nach Osten hin ausgerichtet sind. Die Öffnung befindet sich unten, also auf der dem Eingang am Westportal zugewandten Seite. Auch die handschriftlichen Labyrinthe folgen, von wenigen Ausnahmen abgesehen, diesem Prinzip. Ein frühes Beispiel des Chartres-Typs findet sich in einer im Kloster von Saint-Germain-des-Prés angefertigten Zeichnung aus dem 10. Jahrhundert (Paris, Bibliothèque Nationale, Ms. lat. 13013, Bl. 1r; vgl. Abb. 3). ${ }^{17}$ Im Zentrum lauert ein Minotaurus mit Teufelsfratze, der auf einem Thron sitzt. Die Zeichnung dient als Deckblatt einer Sammelhandschrift mit komputistischen Texten, Annalen und Schriften des Beda Venerabilis (,De natura rerum', ,De temporum ratione', ,De temporibus'). In einer dem Otfrid-Manuskript vergleichbaren Funktion eröffnet das Labyrinth den Kosmos einer Handschrift; wie dieses ist es nach unten hin geöffnet.

Die eigentümliche Struktur der Labyrinthe besteht - so lässt sich zusammenfassend sagen - darin, dass der Rand mit dem Zentrum über Umwege verbunden ist und dabei der vermeintlich entfernteste Punkt dem Mittelpunkt nahe stehen kann. Überformt wird dieses Gefüge durch die Rechtwinkligkeit des Kreuzes, das sich als ordnendes Ganzes über die kaum entwirrbaren Windungen des Labyrinths legt. Eine dieser Struktur in manchen Aspekten vergleichbare Ordnung findet sich in bildlichen Darstellungen, die auf den ersten Blick wenig mit Labyrinthen gemein haben. Zwei davon sollen im Folgenden näher betrachtet werden.

Das erste in diesem Zusammenhang zu nennende Zeugnis beinhaltet wie Otfrids ,Evangelienbuch‘ ein Leben Jesu, diesmal jedoch in bildlicher Form. Es handelt sich um die Bilderdecke der Kirche von St. Martin in Zillis, Graubünden, deren Gemälde vermutlich in der ersten Hälfte des 12. Jahrhunderts entstanden sind. ${ }^{18}$ Der aus Einzeltafeln zusammenge-

17 Vgl. die unter Anm. 6 genannten Arbeiten von Haubrichs, Ordo als Form, S. 286, 289-291; Birkhan, S. 430; Batschelet-Massini, Nr. C 1, S. 50, u. S. 59; Haubrichs, Error inextricabilis, S. 85 f.; Kern, Nr. 177, S. 152.

18 Vgl. Erwin Poeschel, Die romanischen Deckengemälde von Zillis. Erlenbach-Zürich 1941; Beat Brenk, Die romanische Wandmalerei in der Schweiz (Basler Studien zur Kunstgeschichte NF 5). Bern 1963, S. 24-28; Ernst Murbach, Zillis. Die romanische Bilderdecke der Kirche St. Martin. Photographiert und hrsg. v. Peter Heman. Zürich, Freiburg i. Br. 1967; Markus Jenny, Unter dem Siegeszeichen des Kreuzes. Eine theologische Deutung der Zilliser Bilderdecke. Separatabdruck aus der Neuen Zürcher Zeitung vom 26. März 1967, Nr. 816. (ND Ligerz 1993); ders., Zur Anordnung der romanischen Deckenbilder von Zillis. Zeitschrift für Schweizerische Archäologie und Kunstgeschichte 27 (1970), S. 69-92; Ernst Murbach, Die romanische Bilderdecke von Zillis und die Weltkarten des Mittelalters. Sandoz Bulletin 26 (1972), S. 29-42; Susanne Brugger-Koch, Die romanische Bilderdecke von Sankt Martin, Zillis (Graubünden). Stil und Ikonographie. Diss. phil. Basel 1975. Muttenz 1981; Christoph Eggenberger, Die Bilderdecke von St. Martin in Zillis. In: Ursus Brunold u. Lothar Deplazes (Hgg.), Geschichte und Kultur Churrätiens. Festschrift für Pater Iso Müller OSB zu seinem 85. Geburtstag. Disentis 1986, S. 233-270; Christoph Eggenberger u. Dorothee Eggenberger, Malerei des Mittelalters (Ars Helvetica 5). Disentis 1989, S. 104-129 u. ö.; Diether Rudloff, Zillis. Die romanische Bilderdecke der Kirche St. Martin. Mit einem Beitrag von Christoph Eggenberger. Photographiert und hrsg. v. Peter Heman. Basel 1989; Dione Flühler-Kreis, Die romanische Bilderdecke der Kirche St. Martin in Zillis wiederbetrachtet. Bildsystem 


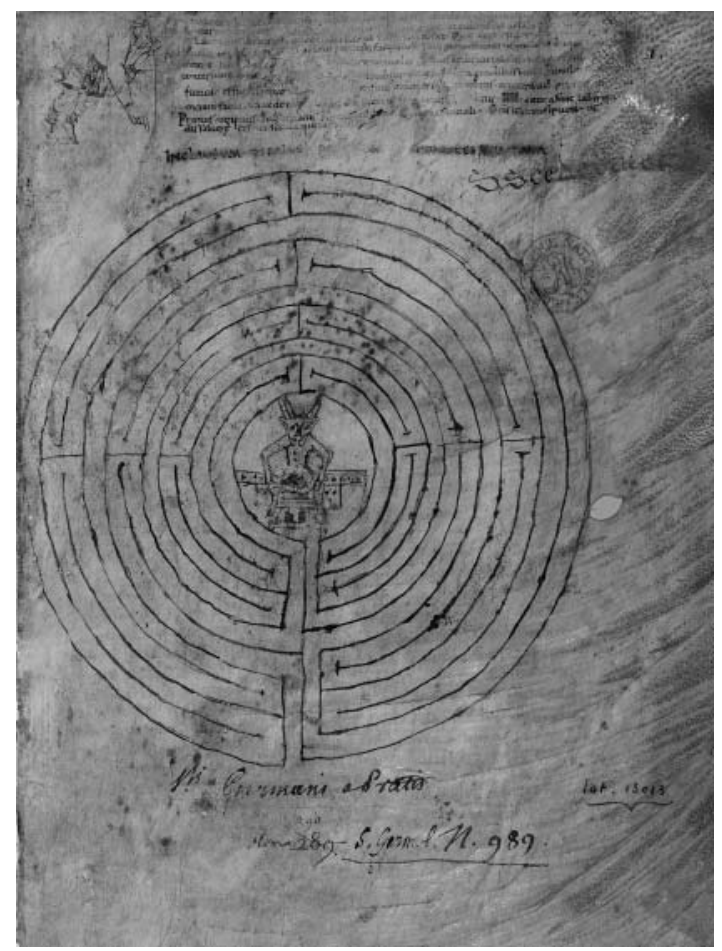

Abb. 3: Labyrinth auf dem Deckblatt einer komputistischen Sammelhandschrift aus Saint-Germain-des-Prés, Paris, Bibliothèque Nationale, Ms. lat. 13013, Bl.1r - Bibliothèque Nationale, Paris

setzte Zyklus, der hier nur in seinen Grundstrukturen beschrieben werden kann, beginnt in der zweiten Zeile mit alttestamentlichen Königen wie David und Salomon als den Vorfahren Jesu und gelangt dann über eine auf zwei Tafeln verteilte Verkündigungsszene zügig zur Geburt und zur Kindheitsgeschichte Christi. Das Leben Jesu erstreckt sich in den folgenden Reihen bis hin zur Passion, die mit einer Dornenkrönung abbricht. Eine sich anschließende Reihe behandelt das Leben des heiligen Martin, dem die Kirche von Zillis geweiht ist.

Betrachtet man die Gesamtanlage des Zyklus, so lässt sich erkennen, dass die Rahmung einzelner Bilder mit einem doppelten Wellenband verziert ist. In der Zusammensetzung ergeben die auf diese Weise gerahmten Bilder eine Kreuzesform, also eben jenes Signum,

und Bildprogramm. Zeitschrift für Schweizerische Archäologie und Kunstgeschichte 50 (1993), S. 223 234; Christoph Eggenberger, Der Mensch lebt nicht vom Brot allein. Die Versuchung Christi in Zillis. Aachener Kunstblätter 60 (1994) (Festschrift für Hermann Fillitz zum 70. Geburtstag), S. 237-244; Christine Bläuer Böhm, Hans Rutishauser u. Marc Antoni Nay (Hgg.), Die romanische Bilderdecke der Kirche St. Martin in Zillis. Grundlagen zur Konservierung und Pflege. Bern, Stuttgart, Wien 1997; darin bes. der Beitrag von Ulrich Ruoff, Mathias Seifert u. Felix Walder, Dendrochronologische Untersuchungen 1994/95, S. 243-265, der aufgrund der in den Brettern der Bildtafeln nachweisbaren Jahrringkurven nahelegt, dass die dafür benötigten Bäume in den Jahren um 1109/1113 gefällt worden sind. Vgl. ferner Jürgen Thies, Die Symbole der Romanik und das Böse. Die Romanische Bilderdecke der Kirche St. Martin in Zillis/Graubünden im Fokus. Nürtingen 2007, zur Datierung bes. S. 31-33, 60 f. 


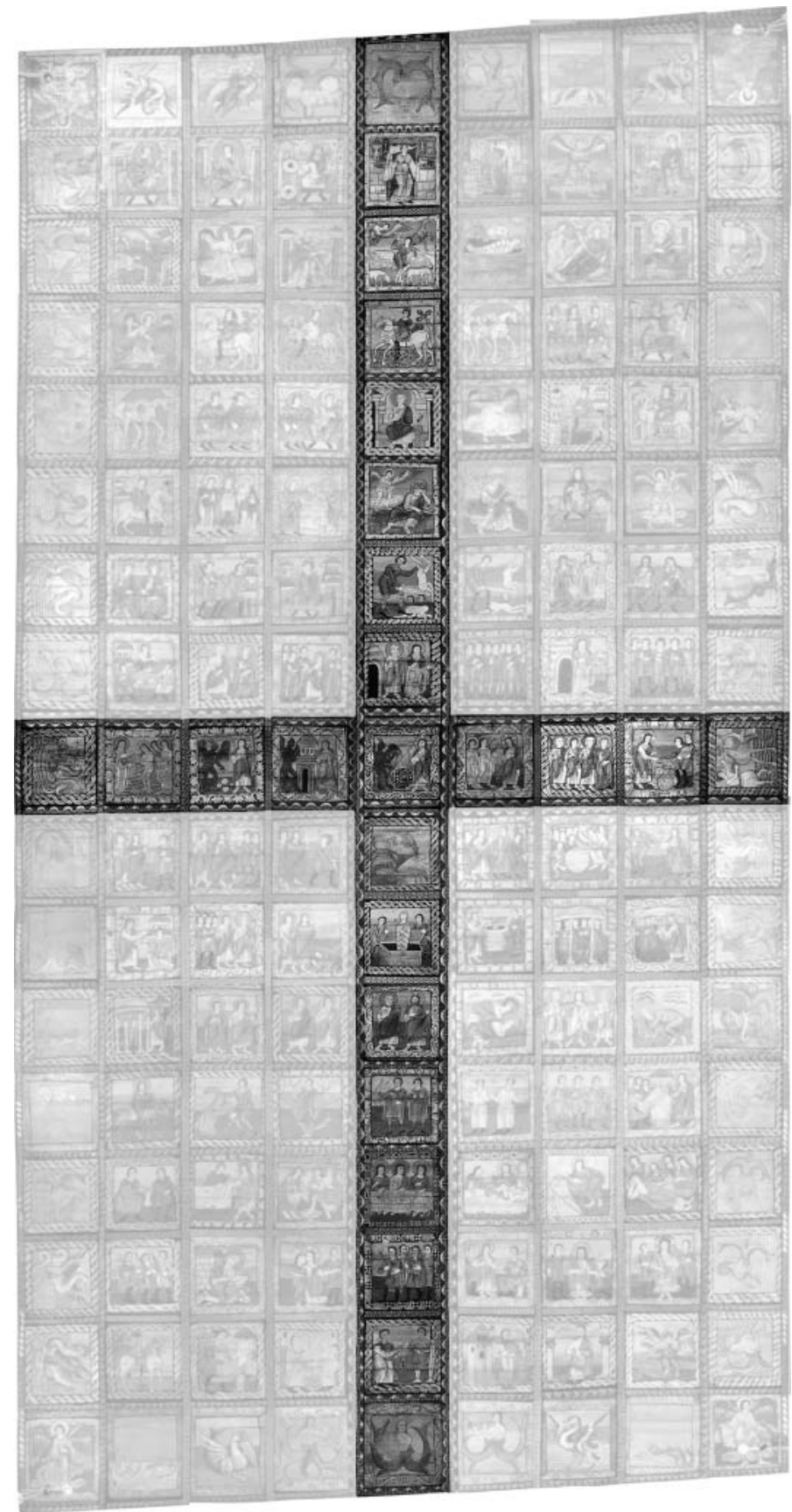

Abb. 4: St. Martin, Zillis, Bilderdecke (Hervorhebung der Kreuzstruktur) - Stiftung Kirchendecke Zillis ${ }^{\circledR}$; Foto: ARGE Restauratoren Kirchendecke Zillis; Emmenegger, Franz, Häusel, Rampa 


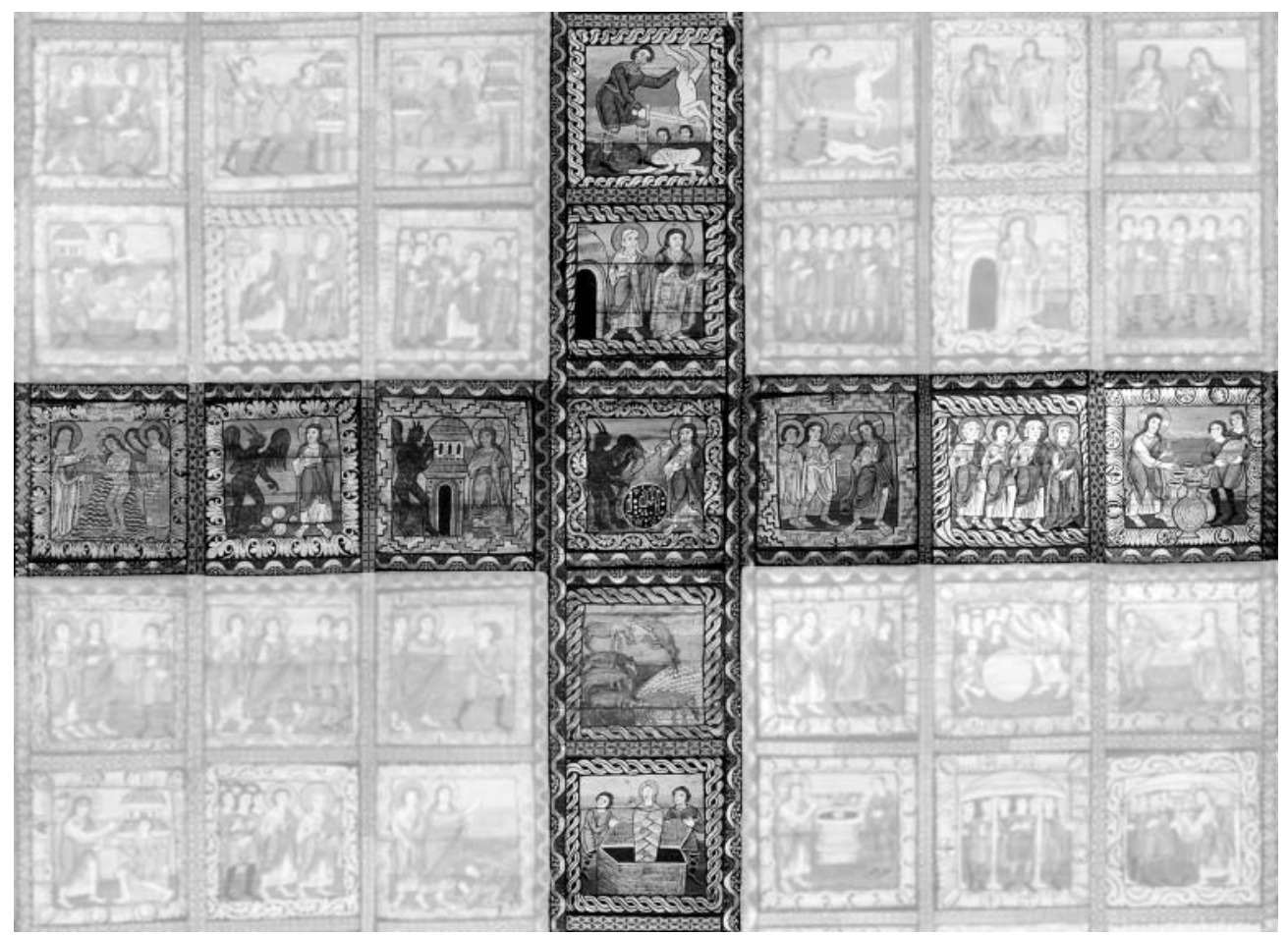

Abb. 5: St. Martin, Zillis, Bilderdecke (Detail) - Stiftung Kirchendecke Zillis ${ }^{\circledR}$; Foto: ARGE Restauratoren Kirchendecke Zillis; Emmenegger, Franz, Häusel, Rampa

das auch die mittelalterlichen Labyrinthe des Chartres-Typs überlagert (vgl. Abb. 4). Blickt man auf den Schnittpunkt von Längs- und Querbalken, dann zeigt sich, dass dort die Versuchung Christi in der Wüste zur Darstellung kommt: Der geflügelte Satan deutet auf eine Erdscheibe oder -kugel ${ }^{19}$ als Sinnbild der Weltreiche und ihrer Pracht, die er Christus gemäß dem Wortlaut des Evangeliums (Matthäus 4, 8 f.; Lukas 4, 5 f.) verheißt (vgl. Abb. 5 und 6). ${ }^{20}$ Dieser im Vergleich mit Otfrids ,Evangelienbuch' beachtliche Befund zeigt, dass Christi Sieg über den Satan im Kreuzpunkt der Darstellung steht. Das Leben Jesu ist auf diese Weise in jenem mundus peccatus angesiedelt, den auch die mittelalterlichen Laby-

19 Im Mittelalter war die Kugelgestalt der Erde bekannt, doch wurde sie bildlich oft in Gestalt einer Scheibe dargestellt; vgl. Jürgen Wolf, Die Moderne erfindet sich ihr Mittelalter - oder wie aus der ,mittelalterlichen Erdkugel' eine ,neuzeitliche Erdscheibe' wurde (Akademie der Wissenschaften und der Literatur. Abhandlungen der geistes- und sozialwissenschaftlichen Klasse, Jg. 2004, Nr. 5; Colloquia Academica. Akademievorträge junger Wissenschaftler, Reihe Geisteswissenschaften, G 2004). Mainz, Stuttgart 2004.

20 Vgl. zur Kreuzesform und zur Zentralstellung des Bildmotivs der Versuchung Christi die unter Anm. 18 genannten Arbeiten von Jenny, Unter dem Siegeszeichen des Kreuzes, bes. S. 22-29; dems., Zur Anordnung der romanischen Deckenbilder, S. 80; Murbach, Zillis, S. 38 f., 42 f.; dems., Die romanische Bilderdecke von Zillis, S. 42; Eggenberger, Malerei des Mittelalters, S. 119-121; Flühler-Kreis, S. 225, 228; Eggenberger, Der Mensch, S. 240; zu Eigenheiten und Parallelbeispielen der Darstellung Brugger-Koch, S. $68 \mathrm{f}$. 


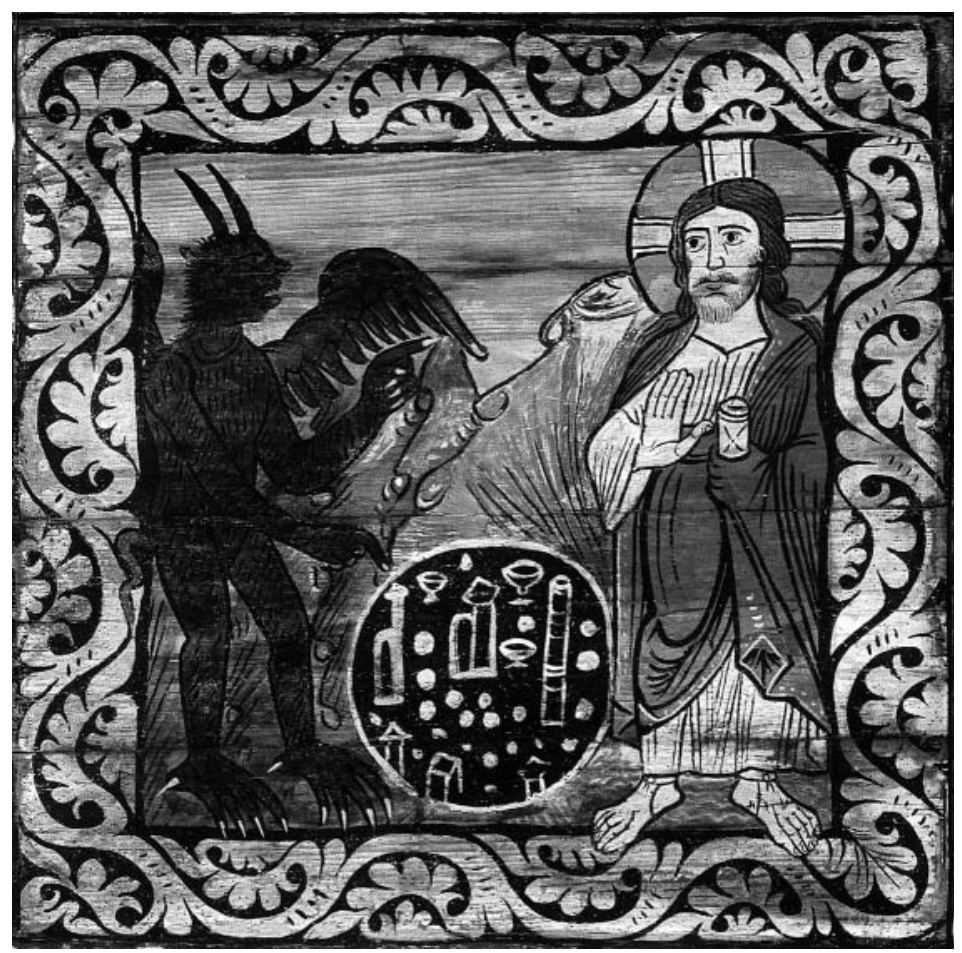

Abb. 6: St. Martin, Zillis, Bilderdecke (Versuchung Christi) - Stiftung Kirchendecke Zillis; Foto: ARGE Restauratoren Kirchendecke Zillis; Emmenegger, Franz, Häusel, Rampa

rinthe mit ihren mäanderartigen Umgängen zur Anschauung bringen und den Christus im Zeichen des Kreuzes überwindet. Fast möchte es scheinen, als sei die Begegnung mit dem Satan, wie sie in der Bilderdecke von Zillis dargestellt ist, ein Relikt des aus der TheseusSage übernommenen Kampfes mit dem Minotaurus. Zumindest gibt es handschriftliche Labyrinth-Zeugnisse, die eine vergleichbare Konfrontation in Szene setzen, so etwa die Darstellung in einer Regensburg-Prüfeninger Handschrift (München, Bayerische Staatsbibliothek, Clm 14731, Bl. 82v), die mit ihrer Entstehung gegen Ende des 12. Jahrhunderts von jener der Bilderdecke in Zillis nicht allzu weit entfernt ist (vgl. Abb. 7). ${ }^{21}$

Es muss an dieser Stelle betont werden, dass die Anordnung der Bilder von Zillis bis zu einem gewissen Grad beweglich ist. Die einzeln angefertigten Gemälde können in den Nuten des Trägergerüsts verschoben werden. Die heutige Anordnung folgt im Wesentlichen einer sorgfältigen Rekonstruktion der Jahre 1938 bis $1940 .{ }^{22}$ Sie wurde in der Folge in

21 Vgl. Albert Boeckler, Die Regensburg-Prüfeninger Buchmalerei des 12. und 13. Jahrhunderts (Miniaturen aus Handschriften der Bayerischen Staatsbibliothek 8). München 1924, S. 64 f.; sowie die unter Anm. 6 genannten Arbeiten von Batschelet-Massini, Nr. A 9, S. 47 f.; Haubrichs, Error inextricabilis, Nr. 12, S. 79-81; Kern, Labyrinth (Anm. 6), Frontispiz und Nr. 194, S. 165 (mit weiterer Literatur).

22 Die Ergebnisse wurden in der 1941 erschienenen Arbeit von Poeschel (Anm. 18) publiziert. 


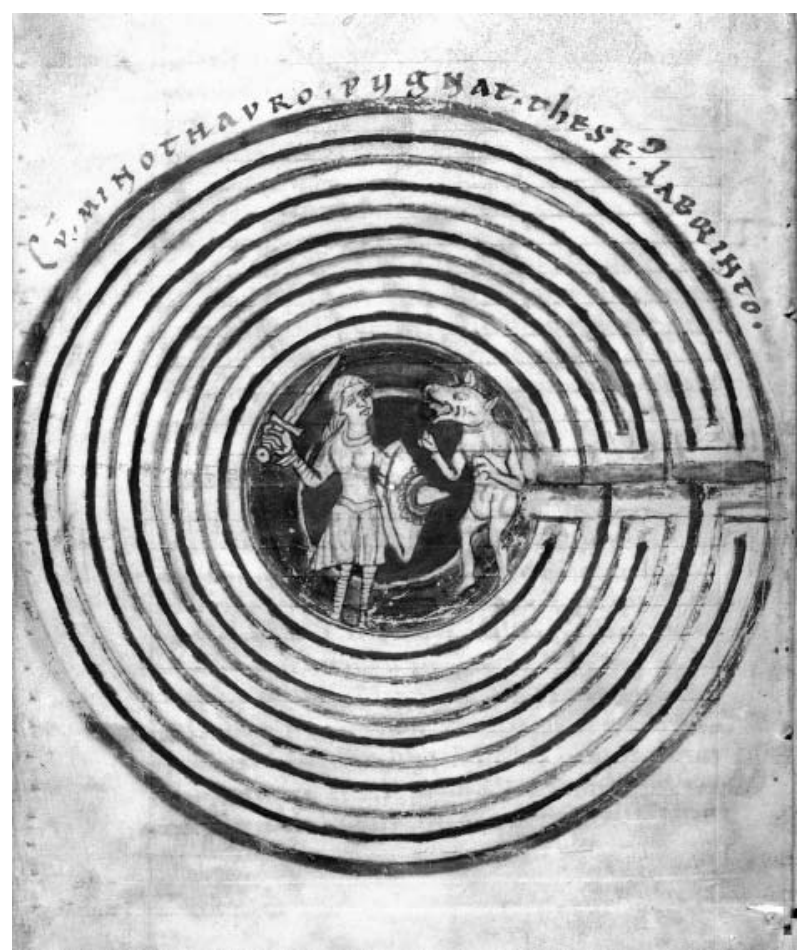

Abb. 7: Labyrinth in einer Regensburg-Prüfeninger Handschrift, München, Bayerische Staatsbibliothek, Clm 14731, Bl. 82v - Bayerische Staatsbibliothek, München

einzelnen Details korrigiert; dabei stand jedoch die Zentralstellung der Versuchung Christi durch den Satan nie in Frage. ${ }^{23}$

Ein weiteres charakteristisches Merkmal der Bilderdecke ist deren äußere Randleiste. An den Bordüren tummeln sich Meerwesen und Ungeheuer, die vermutlich den Ur-Ozean repräsentieren - als „Inbegriff der Bedrohung [...] des Kosmos durch das Chaos. “24 Sie werden in den äußersten Ecken von Engeln mit Hörnern ergänzt, die gleichermaßen als Personifikationen der vier Winde wie als Verkünder des Jüngsten Gerichts anzusehen sind. Damit sind der Sieg Christi über den Satan im Zentrum und das in den Randleisten gegenwärtige „Andere“ der Heilsgeschichte spannungsvoll aufeinander bezogen. Eine Verbindung schafft das sich über die Einzelszenen hin in vier Richtungen erstreckende Kreuz. Es überhöht die Einzeldarstellungen, indem es die mit der Dornenkrönung abbrechende Leidensgeschichte des Bilderzyklus erst vollendet. Auf diese Weise verklammert es die sich zwischen Zentrum und Rändern erstreckende Heilsgeschichte.

23 Vgl. zu den nach Poeschels Rekonstruktion vorgebrachten Änderungsvorschlägen den Forschungsbericht und die Neuansätze bei Brugger-Koch (Anm. 18), S. 91 f.; ferner Eggenberger, Malerei des Mittelalters (Anm. 18), S. 111; Flühler-Kreis (Anm. 18), S. 226.

24 Jenny, Unter dem Siegeszeichen des Kreuzes (Anm. 18), S. 13. Zu den Darstellungen in den Randzonen ausführlich Brugger-Koch (Anm. 18), S. 29-38. 


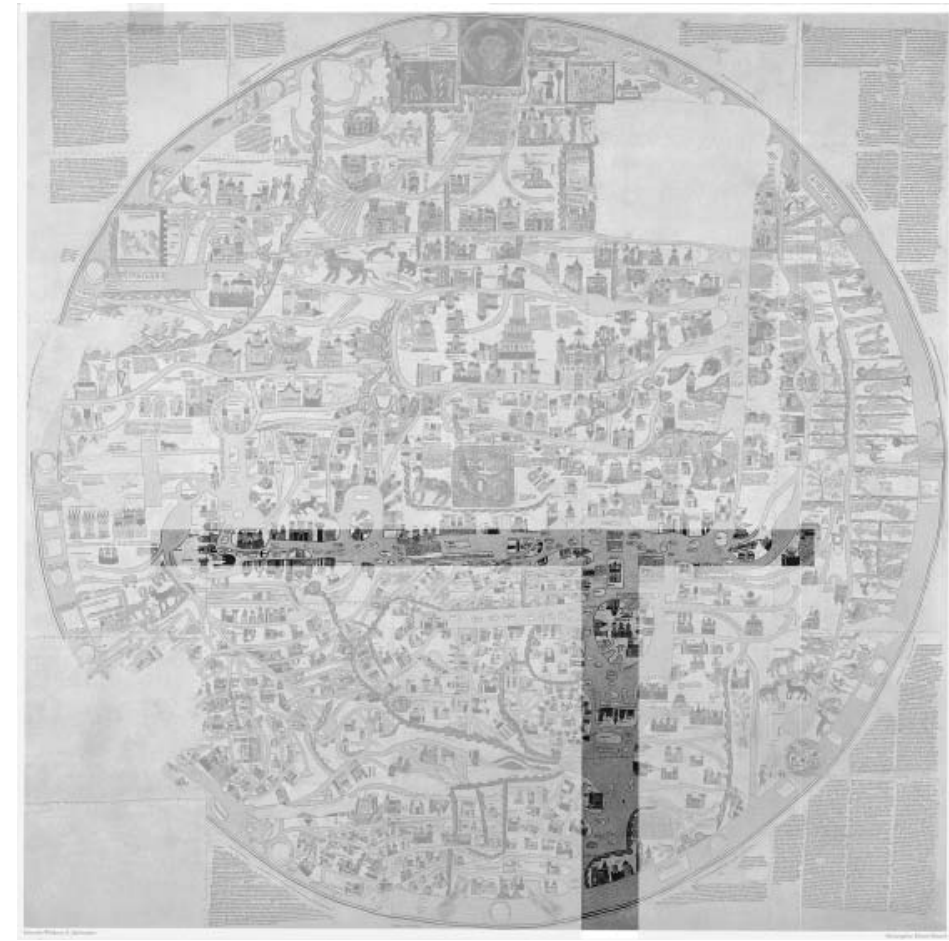

Abb. 8: Ebstorfer Weltkarte (Struktur des T-Schemas) - Akademie Verlag, Berlin

Eine solche Verklammerung findet sich auch in einem zweiten Darstellungstyp, der sich mit den mittelalterlichen Labyrinthen vergleichen lässt, jenem der Weltkarten. ${ }^{25}$ Als Beispiel sei die Ebstorfer Weltkarte genannt, die im 13. Jahrhundert (wohl erst gegen 1300)

25 Zur Vergleichbarkeit auch Kern (Anm. 6), S. 142, 217 f. Zum Quellentyp der Weltkarten Jörg-Geerd Arentzen, Imago mundi cartographica. Studien zur Bildlichkeit mittelalterlicher Welt- und Oekumenekarten unter besonderer Berücksichtigung des Zusammenwirkens von Text und Bild. München 1984 (Münstersche Mittelalter-Schriften 53); Hubert Herkommer, Der St. Galler Kodex als literarhistorisches Monument. In: Rudolf von Ems, ,Weltchronik‘. Der Stricker, ,Karl der Große‘. Kommentar zu Ms 302 Vad. Hrsg. v. der Kantonsbibliothek (Vadiana) St. Gallen und der Editionskommission (Ellen J. Beer, Johannes Duft, Hubert Herkommer, Karin Schneider, Stefan Sonderegger, Peter Wegelin). Luzern 1987, S. 127-273, bes. S. 224 f.; Brigitte Englisch, Ordo orbis terrae. Die Weltsicht in den Mappae mundi des frühen und hohen Mittelalters (Orbis mediaevalis - Vorstellungswelten des Mittelalters 3). Berlin 2002; Rudolf Simek, Erde und Kosmos im Mittelalter. Das Weltbild vor Kolumbus. München 1992, bes. S. 153-161; Paul Zumthor, La mesure du monde. Représentation de l'espace au Moyen Age (Poétique). Paris 1993, S. 317-344; ders., Mappa mundi und Performanz. Die mittelalterliche Kartographie. In: JanDirk Müller (Hg.), „Aufführung“ und „Schrift“ in Mittelalter und Früher Neuzeit (Germanistische Symposien. Berichtsbände 17). Stuttgart, Weimar 1996, S. 317-327; Jürg Glauser u. Christian Kiening (Hgg.), Text - Bild - Karte. Kartographien der Vormoderne (Rombach Wissenschaften, Reihe Litterae 105). Freiburg i. Br., Berlin, Wien 2007; Anna-Dorothee von den Brincken, Studien zur Universalkartographie des Mittelalters. Hrsg. v. Thomas Szabó (Veröffentlichungen des Max-Planck-Instituts für Geschichte 229). Göttingen 2008. 


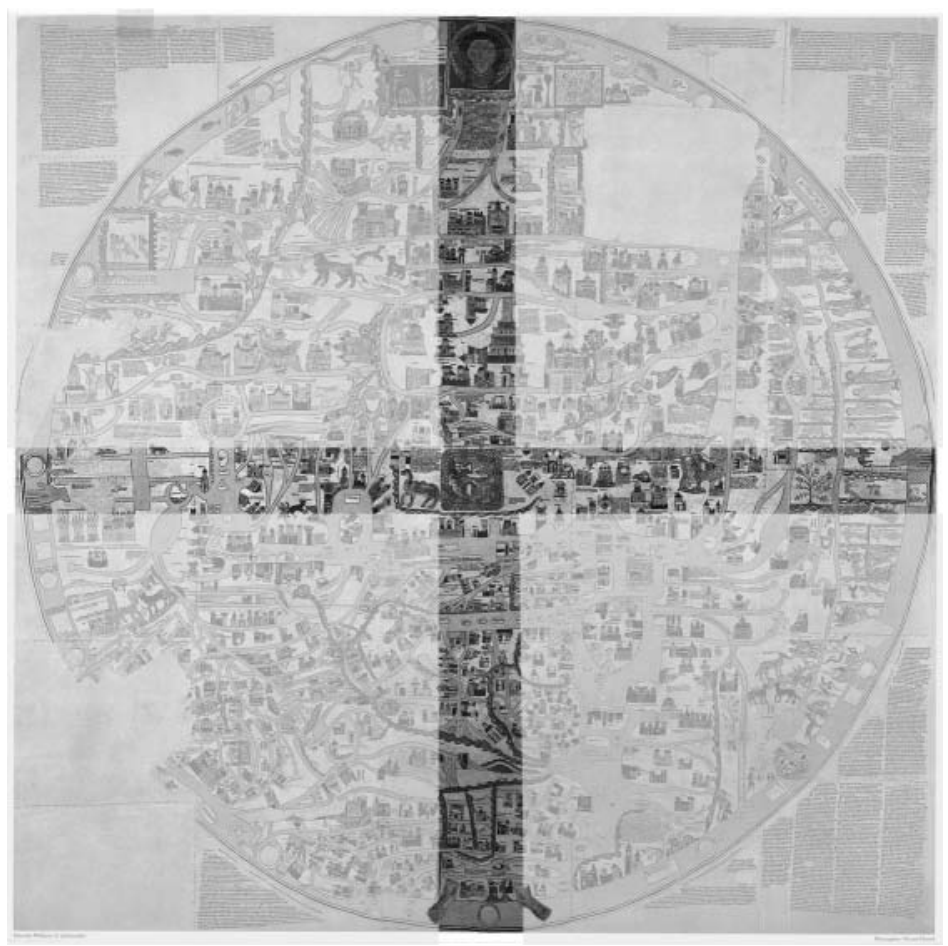

Abb. 9: Ebstorfer Weltkarte (Hervorhebung der Kreuzstruktur) - Akademie Verlag, Berlin

im niedersächsischen Frauenkloster Ebstorf bei Lüneburg angefertigt wurde. ${ }^{26}$ Im Medium von Text und Bild bringt sie die kreisförmig vom Ozean umspülte Oekumene (,die bewohnte Erde“) zur Anschauung. Die Karte ist wie die erwähnten Labyrinthe „orientiert“, d. h. ihr oberer Teil erstreckt sich nach Osten. In dieser Ausrichtung stimmt sie im Übrigen mit der Bilderdecke von Zillis überein, denn auch dort weist der Anfang des Lebens Jesu

26 Vgl. die nunmehr maßgebliche Edition: Die Ebstorfer Weltkarte. Kommentierte Neuausgabe in zwei Bänden. Hrsg. v. Hartmut Kugler. Bd. 1: Atlas, Bd. 2: Untersuchungen und Kommentar. Berlin 2007 (mit der einschlägigen Forschungsliteratur). Neuere Forschungsliteratur: Jürgen Wilke, Die Ebstorfer Weltkarte (Veröffentlichungen des Instituts für historische Landesforschung der Universität Göttingen 39 ). 2 Bde. Bielefeld 2001; Nathalie Kruppa u. Jürgen Wilke (Hgg.), Kloster und Bildung im Mittelalter (Studien zur Germania Sacra 28; Veröffentlichungen des Max-Planck-Instituts für Geschichte 218). Göttingen 2006 (mit zahlreichen Beiträgen zur Ebstorfer Weltkarte). Semiotische Zugänge erschließt Cornelia Herberichs, ... quasi sub unius pagine visione coadunavit. Zur Lesbarkeit der Ebstorfer Weltkarte. In: Glauser/Kiening (Anm. 25), S. 201-217. - Die Datierungsversuche der Karte schwanken zwischen ca. 1208/ 18 (zur Regierungszeit des Welfenkaisers Otto IV. und vielleicht mit Gervasius von Tilbury als Autor?) und um 1300; vgl. den Forschungsbericht bei Englisch (Anm. 25), S. 469-471; mit starken Argumenten für die Spätdatierung zuletzt Wilke, Die Ebstorfer Weltkarte, zusammenfassend Bd. 1, S. 282-286, und die Ausgabe von Kugler, Bd. 2, S. 69. 
gegen den Chor, also gen Osten hin. Wie dort ist das ins Bild gesetzte Geschehen vom Element des Wassers umgeben. ${ }^{27}$

Von Geschehen lässt sich bei der Ebstorfer Weltkarte tatsächlich sprechen, denn diese vereint in ihrer synchronen Darstellungsform zahlreiche Ereignisse der antiken Sagenwelt und der christlichen Heilsgeschichte. Die Anlage folgt dem sogenannten T-Schema: In der Form des Buchstabens T, dessen Querbalken unterhalb der Mitte des von der Erde beschriebenen Kreises anzusetzen ist, trennen Wasserläufe die Kontinente Asien (in der oberen Hemisphäre), Europa und Afrika (in der unteren linken bzw. rechten Hälfte; vgl. Abb. 8).

Zusammengehalten aber wird dieses Weltbild vom Leib des Erlösers Christus, dessen eingerahmtes Haupt zuoberst, neben dem leicht nach links verschobenen irdischen Paradies sichtbar wird; die Füße nehmen den unteren Rand, die Hände die Seitenränder des Erdkreises ein. ${ }^{28}$ In der Körpergestalt Christi prägt sich damit die dem Buchstaben $\mathrm{T}$ analoge Kreuzesform dem Weltganzen auf (vgl. Abb. 9). Im Zentrum der Karte steht die Stadt Jerusalem, deren quadratische Anlage - ähnlich wie die Ausdehnung des Kreuzes in Otfrids Hymnus - auf die vollkommene Vierzahl verweist: Als Nabel der Welt birgt Jerusalem in seiner Mitte den auferstandenen Christus, dessen nach links, also nach Norden gerichteter Leib auf diese Weise ein zweites Mal in der Weltkarte zur Erscheinung kommt: Der Mikrokosmos des Auferstandenen entspricht dem Makrokosmos des die Welt umfangenden Erlösers. Aus dem Kämpfer gegen den Satan, wie er in den Labyrinthen und in Zillis dargestellt wird, ist hier der Sieger über den Tod geworden.

Auffällig sind die ähnlich wie in Zillis an den Rändern der Welt angesiedelten Ungeheuer und Monstren (vgl. Abb. 10). ${ }^{29} \mathrm{Zu}$ ihnen gehören - in unmittelbarer Nachbarschaft der ausgestreckten linken Hand der Erlöserfigur Christi, also in der äußersten südlichen Erdregion - ein Volk ohne Zunge, das sich durch Gebärden verständigt (Gens que lingua caret, nutibus ac motibus utuntur), ferner die riesenhaften Syrbotae in Äthiopien (Sorbete Ethyopes, qui longi sunt ad pedes XII), außerdem ein Volk mit Unterlippen, die so weit hervorstehen, dass sie gegen die Sonne schützen können (Gens que habet ora concreta labioque promoventi, ut contra solis radios se tegat), die Troglodyten, die so schnell sind,

27 Bezüge zu Darstellungsprinzipien der Weltkarten werden auch in den Forschungen zu Zillis wiederholt hergestellt. Vgl. unter den in Anm. 18 erwähnten Arbeiten besonders Poeschel, S. 11 f.; Murbach, Zillis, S. 42; ders., Die romanische Bilderdecke von Zillis, passim; Flühler-Kreis, S. 229-231. Vorsichtiger, aber nicht prinzipiell ablehnend Brugger-Koch, S. 27-29, 88; Eggenberger, Malerei des Mittelalters, S. $110 \mathrm{f}$. (beide auf das Vorbild der Darstellung von Meereslandschaften verweisend).

28 Vgl. Arentzen (Anm. 25), S. 267-274; Simek (Anm. 25), S. 95-102; Hubert Herkommer, Frau Welt und Fortuna, Kreis und Quadrat. Weltbilder des europäischen Mittelalters. In: Maja Svilar u. Stefan Kunze (Hgg.), Weltbilder (Collegium Generale Universität Bern, Kulturhistorische Vorlesungen 1991/92). Bern u. a. 1993, S. 177-228, hier S. 209-211; Marina Münkler u. Werner Röcke, Der ordo-Gedanke und die Hermeneutik der Fremde im Mittelalter: Die Auseinandersetzung mit den monströsen Völkern des Erdrandes. In: Herfried Münkler unter Mitarb. v. Karin Messlinger u. Bernd Ladwig (Hgg.), Die Herausforderung durch das Fremde (Interdisziplinäre Arbeitsgruppen 5). Berlin 1998, S. 701-766, bes. S. $744-$ 746; Beat Wolf, Jerusalem und Rom: Mitte, Nabel - Zentrum, Haupt. Die Metaphern Umbilicus mundi und Caput mundi in den Weltbildern der Antike und des Abendlands bis in die Zeit der Ebstorfer Weltkarte. Bern u. a. 2010, S. $28-32$.

29 Vgl. Simek (Anm. 25), S. 110-123; Münkler/Röcke (Anm. 28); Marina Münkler, Monstra und mappae mundi: die monströsen Völker des Erdrands auf mittelalterlichen Weltkarten. In: Glauser/Kiening (Anm. 25), S. 149-173. 


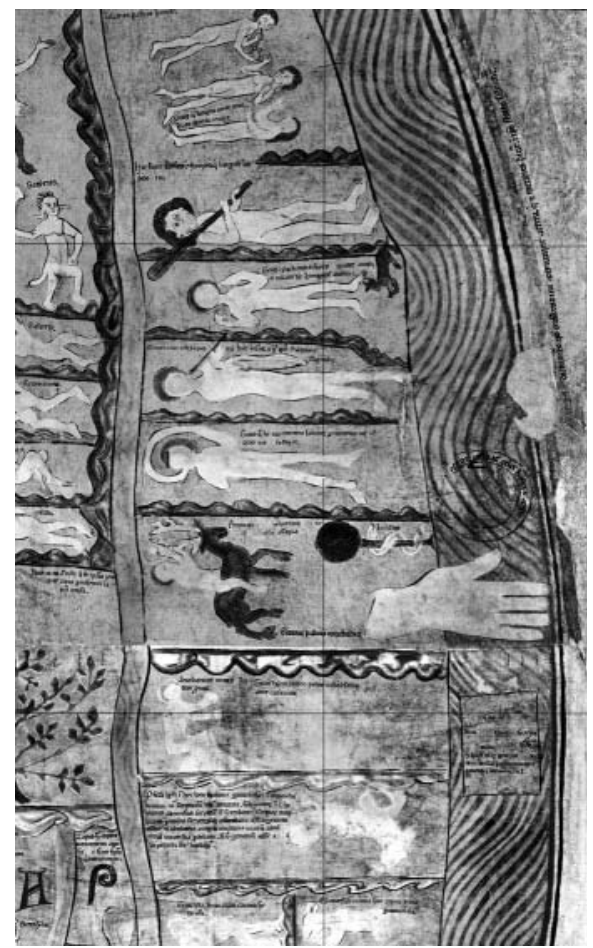

Abb. 10: Ebstorfer Weltkarte (Monstren und linke Hand Christi am Bildrand) - Akademie Verlag, Berlin

dass sie das Jagdwild im Laufen einholen können (Tracotidi tanta velocitate pollent, ut feras cursu assequantur), die Artobatitae, die vorn übergeneigt gehen (Artobatitis mos est incedere pronis), die Kynokephalen, ein Volk mit Hundeköpfen und vorstehenden Mäulern (Cynocefali canina habent capita et ora prominentia). ${ }^{30}$

Wie die Hand Christi am südlichen Ausläufer der Oekumene anzeigt, sind auch diese Völker Teil der christlichen Weltordnung. Das Argument für ihre Zugehörigkeit findet sich bereits in der Patristik. Augustinus stellt in seinen Schriften die Behauptung auf, dass in der gottgewollten Ordnung ,nichts geschaffen sei, das nicht auch schön wäre. “31 In seiner

30 Die lateinischen Texte finden sich jeweils als Beischriften. Vgl. Münkler (Anm. 29), S. 163 - 168 (mit weiteren Beispielen), sowie die Ausgabe von Kugler (Anm. 26), Bd. 1, Sektionen 28 und 35, S. 84 f., 98 f., und die Quellen- bzw. Parallelnachweise (u. a. Plinius, Solinus, Isidor von Sevilla, die ,Mirabilia mundi'-Handschrift Ms. Ludwig XV, 4 des J. Paul Getty Museums, Los Angeles) ebd., Bd. 2, S. 154, 186-189. Zur Darstellung der südlichen Erdregion vgl. Hartmut Kugler, Himmelsrichtungen und Erdregionen auf mittelalterlichen Weltkarten. In: Glauser/Kiening (Anm. 25), S. 175-199, hier S. 195 f. - Randphänomene als Eigenart mittelalterlicher Kunst behandelt Michael Camille, Image on the Edge. The Margins of Medieval Art (Essays in Art and Culture). London 1992 (ND London 2008), speziell zu den Weltkarten S. 14-16.

31 Aurelius Augustinus, De vera religione. Die wahre Religion. Zweisprachige Ausgabe. Eingel., übers. u. hrsg. v. Josef Lössl (Augustinus. Opera/Werke. L. Schriften zu grundsätzlichen Glaubensinhalten 68). 
Abhandlung ,Vom Gottesstaat" leitet er den Ausdruck monstrum von monstrare (,zeigen“) $\mathrm{ab}$, versteht die missgestalteten Ungeheuer mithin als Zeichen des göttlichen Schöpfungsplans. $^{32}$ An einer anderen Stelle desselben Textes erklärt er: „Aber wer das Ganze nicht zu überschauen vermag, wird durch die vermeintliche Hässlichkeit eines Teilstückes beleidigt, weil er nicht erkennt, wozu es passt und worauf es sich bezieht." ${ }^{33}$

Es ist der bis in unsere Tage diskutierte Gedanke der ,einen“ Welt, ${ }^{34}$ welcher auf diese Weise zum Ausdruck kommt. Auf der Ebstorfer Weltkarte wird diese Einheit im Körper des göttlichen Erlösers sichtbar. Der Rand der Welt bleibt auf das Zentrum, hier auf das Geschehen der Auferstehung am Ostermorgen, bezogen. Letztlich liegt dieses Strukturprinzip auch den beiden anderen betrachteten Bildtypen zugrunde: den Labyrinthen ebenso wie der Bilderdecke von Zillis. Nur wird dort der Mittelpunkt nicht von der Pose des Siegers, sondern von der noch ungewiss erscheinenden Auseinandersetzung des Erlösers mit seinem Widersacher beherrscht. In der Begegnung Christi mit dem Satan steht gerade jener Erdkreis zur Disposition, der auf den Weltkarten dargestellt ist (vgl. Abb. 6). Die Gefährdung des göttlichen Kosmos durch ein „Anderes“, ein diesem Kosmos eigenes und ihm zugleich äußerlich bleibendes „Fremdes“ scheint in der Darstellung von Zillis spannungsvoll gewahrt.

\section{Ränder der Diskurse}

Nach den erwähnten Bildbeispielen sollen in einem nächsten Schritt diskursive Randphänomene behandelt werden. Worum es dabei geht, sei vorab an einem Strukturprinzip der mittelalterlichen Schriftpraxis erläutert. Eine im 10. Jahrhundert vermutlich im westdeutschen Raum angefertigte Handschrift, die den bereits erwähnten ,Aeneis'-Kommentar des Servius überliefert, dokumentiert in ihrem Layout typisch mittelalterliche Strategien der Textkommentierung (Paris, Bibliothèque Nationale, Nouv. acq. lat. 2059, Bl.2r; vgl. Abb. 11): Vergils Text steht dabei im Zentrum, einzelne Wörter sind durch Glossen überschrieben. Den Hauptteil des Kommentars aber nehmen die Randfelder ein, von denen der Ausgangstext regelrecht umzäunt wird. Dieses Layout ist typisch für die Anlage mittelalter-

Paderborn 2007, XLI, 77, S. 208: Nihil enim est ordinatum, quod non sit pulchrum. Vgl. Paul Michel, ,Formosa deformitas‘. Bewältigungsformen des Hässlichen in mittelalterlicher Literatur (Studien zur Germanistik, Anglistik und Komparatistik 57). Bonn 1976, S. 43; Max Wehrli, Literatur im deutschen Mittelalter. Eine poetologische Einführung (Universal-Bibliothek 8038). Stuttgart 1984, S. 151-155 („Dämonische und elegische Schönheit. Das Hässliche“). - Eine vergleichbare Rechtfertigung findet sich in den ,Etymologiae“ Isidors von Sevilla (Anm. 1), wo es von den monströsen Wesen heißt: non sunt contra naturam, quia divina voluntate fiunt. (XI, 3, 1). Vgl. Münkler/Röcke (Anm. 28), S. 725; ferner Flühler-Kreis (Anm. 18), S. 231 mit Anm. 27.

32 Sancti Aurelii Augustini episcopi De civitate Dei libri XXII. Hrsg. v. Bernhard Dombart u. Alfons Kalb. 2 Bde. 4. Aufl. Leipzig 1928 (ND Darmstadt 1981), XXI, 8, S. 507, Z. 12 f.: Monstra sane dicta perhibent a monstrando. Vgl. Münkler/Röcke (Anm. 28), S. 724

33 De civitate Dei (Anm. 32), XVI, 8, S. 136, Z. 10-12: Sed qui totum inspicere non potest, tamquam deformitate partis offenditur, quoniam cui congruat et quo referatur ignorat. Deutsche Übersetzung aus: Aurelius Augustinus, Vom Gottesstaat (De civitate Dei). Aus dem Lateinischen übertragen v. Wilhelm Thimme, eingel. und komm. von Carl Andresen (dtv 34393). 2 Bde. in einem Band. München 2007, Bd. 2, S. 294. Vgl. Münkler/Röcke (Anm. 28), S. 731, sowie Herkommer (Anm. 25), S. 229 f. mit Anm. $474 \mathrm{f}$.

34 Vgl. z. B. Hans Küng, Projekt Weltethos. 11. Aufl. München 2008. 


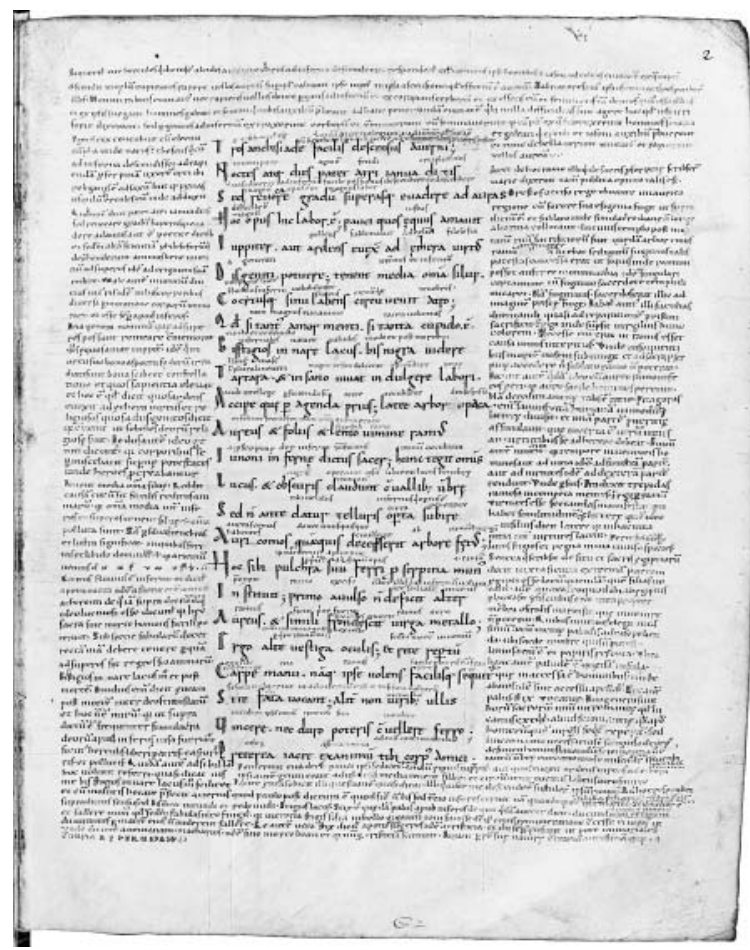

Abb. 11: Servius, ,Aeneis'-Kommentar, Paris, Bibliothèque Nationale, Nouv. acq. lat. 2059, Bl. 2r - Bibliothèque Nationale, Paris

licher Kommentare, die auf diese Weise den Grundtext umfangen. Auch heute noch verfährt literaturwissenschaftliche Arbeit ähnlich: Die Quellen werden von Sekundärtexten umstellt und, wenn nicht qualitativ, so doch quantitativ geradezu überwuchert. Der am Rand des Ausgangstextes positionierte Text drängt dabei ins Zentrum, ja beansprucht dessen Platz. Dieser spezifische Status von Marginalität, der in den mittelalterlichen Kommentaren besonders anschaulich wird, ${ }^{35}$ soll in den folgenden Ausführungen behandelt werden.

In der nunmehr vorzustellenden Handschrift findet sich ebenfalls eine Weltkarte (München, Universitätsbibliothek, $2^{\circ}$ Cod. ms. 731, Bl. 140vb; vgl. Abb. 12). Diese mappa mun$d i$,en miniature“ zeigt wie die Ebstorfer Weltkarte die drei Kontinente Europa, Asien und Afrika. Das Paradies ragt V-förmig in diese Weltordnung hinein, im Mittelpunkt befindet sich Jerusalem. Die Zeichnung verbindet den Typus der T-Karte mit jenem der sogenann-

35 Martin Irvine, The Making of Textual Culture. Grammatica and Literary Theory, 350-1100 (Cambridge Studies in Medieval Literature 19). Cambridge 1994, beschreibt dieses Verfahren als ,,interpretative supplement": ,the writing in the margins, this place outside the text, is really the inside, the inner meaning of the text unfolded to a space outside the text" (S. $391 \mathrm{f}$; d dort S. 388 auch die Abbildung der Pariser Servius-Handschrift). 


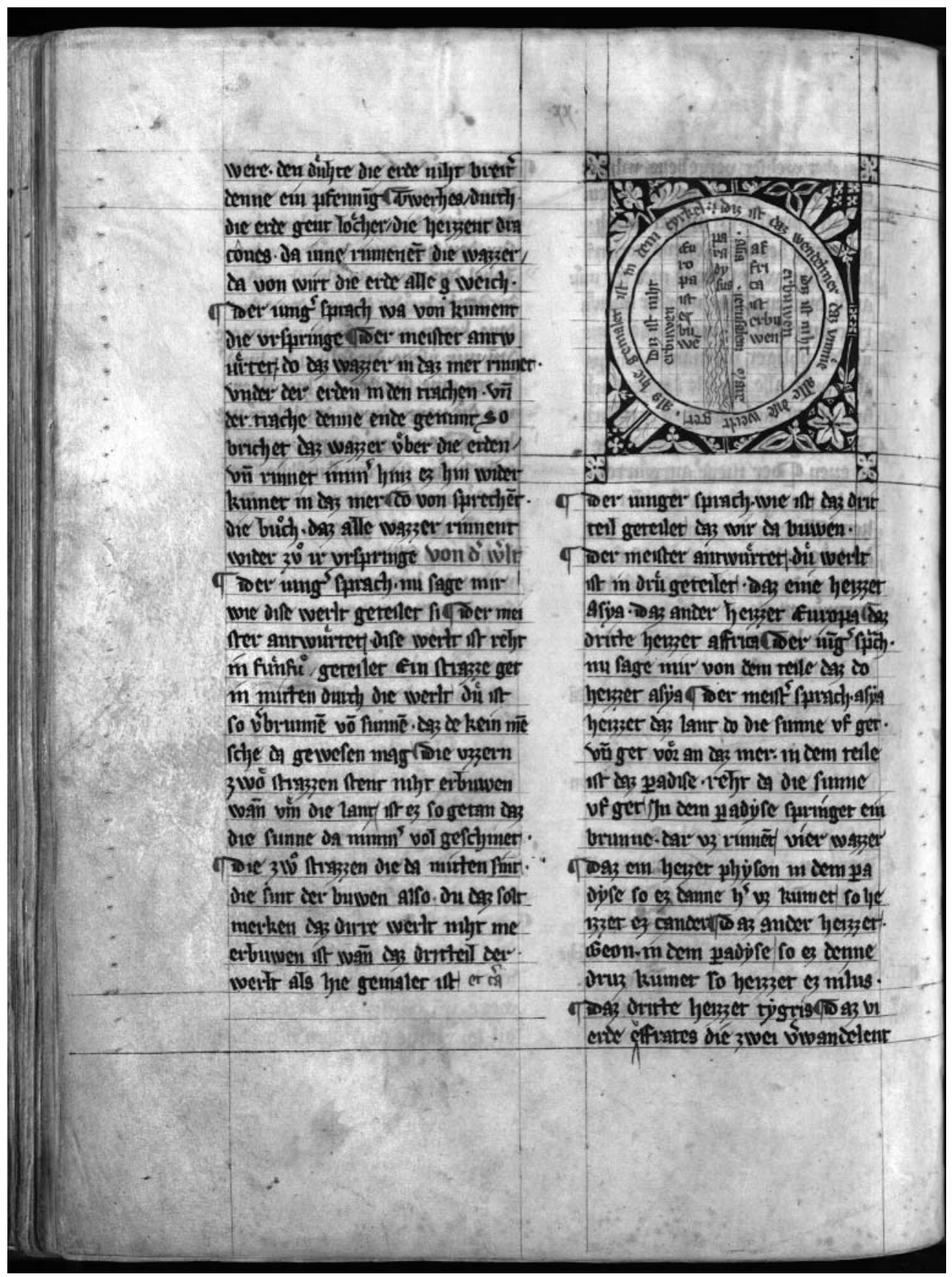

Abb. 12: Weltkarte im ,Lucidarius', Hausbuch des Michael de Leone, München, Universitätsbibliothek, $2^{\circ}$ Cod. ms. 731, Bl. 140v - Universitätsbibliothek, München 
ten Zonenkarten, in denen die Welt in fünf Klimazonen aufgeteilt ist. ${ }^{36}$ Von den Kontinenten Europa und Afrika heißt es in einer deutschsprachigen Beischrift, sie seien erbuwen (,,bewohnt"), während die beiden daran angrenzenden Klimazonen gemäß der Beischrift niht erbuwen (,unbewohnt") sind. Umflossen wird die Erde von einem hier wendelmer genannten Ozean.

Die Darstellung entstammt dem sogenannten ,Hausbuch“, das Michael de Leone (gest. 1355), der Protonotar des Würzburger Bischofs, in der Mitte des 14. Jahrhunderts anlegte. ${ }^{37}$ Die Handschrift umfasst literarisch-didaktische Texte verschiedener Gattungen, darunter auch das Lehrwerk ,Lucidarius“ (nach dem lateinischen ,Elucidarium“ des Honorius Augustodunensis), zu dem die kleine Weltkarte gehört, sowie neben Liedern Reinmars von Hagenau und Walthers von der Vogelweide die Spruchsammlung Freidanks mit dem Titel ,Bescheidenheit“ (im Sinne von „Fähigkeit zu unterscheiden,“ „Urteilsfähigkeit“"). Dieses letztere, in seiner Überlieferung sehr bewegliche Textcorpus besteht aus Reimpaarsprüchen von pointierter Kürze, die meist in einem Verspaar sprichwortartige Lehren formulieren. ${ }^{38}$ Mit einigen Aussagen bezieht sich Freidank auch auf aktuelle Fragen seiner Lebenszeit, des früheren 13. Jahrhunderts. Er erwähnt die Auseinandersetzungen zwischen Kaiser und Papst sowie den Fall der Kreuzfahrerstadt Akkon.

36 Vgl. zur Verbindung der beiden Kartentypen Arentzen (Anm. 25), S. 94. Zur Karte selbst Christa Bertelsmeier-Kierst, Das ,Hausbuch“ des Michael de Leone. Zu Programm und Struktur der Sammlung. In: Horst Brunner (Hg.), Würzburg, der Große Löwenhof und die deutsche Literatur des Spätmittelalters (Imagines medii aevi 17). Wiesbaden 2004, S. 199-210, hier S. 205; Helgard Ulmschneider, Von der ordenunge dirre welte. Zur ältesten Weltkarte in einem deutschsprachigen Text, der ,mappa mundi“ im „Lucidarius‘. In: Freimut Löser u. Ralf G. Päsler (Hgg.), Vom vielfachen Schriftsinn im Mittelalter. Festschrift für Dietrich Schmidtke (Schriften zur Mediävistik 4). Hamburg 2005, S. 579-605, hier S. 586 f. und Abb. 6.

37 Erhalten ist mit der Handschrift München, Universitätsbibliothek, $2^{\circ}$ Cod. ms. 731, nur der zweite Band. Vom ersten Band existieren lediglich einige Blätter (München, Bayerische Staatsbibliothek, Cgm 195/I; Nürnberg, Germanisches Nationalmuseum, Hs. 9030). Neben dem ,Hausbuch“ hat Michael de Leone eine zweite Sammelhandschrift angelegt, das sogenannte ,Manuale‘ (Würzburg, Universitätsbibliothek, cod. M. p. misc.f. 6), in dem sich mitunter dieselben Texte finden. Vgl. die Faksimileausgabe des ,Hausbuchs': Das Hausbuch des Michael de Leone (Würzburger Liederhandschrift) der Universitätsbibliothek München ( $2^{\circ}$ Cod. ms. 731). In Abbildung hrsg. v. Horst Brunner (Litterae 100). Göppingen 1983. Zur Handschrift in Auswahl (jeweils mit weiterer Literatur): Gisela Kornrumpf u. Paul-Gerhard Völker, Die deutschen mittelalterlichen Handschriften der Universitätsbibliothek München (Die Handschriften der Universitätsbibliothek München 1). Wiesbaden 1968, S. 66-107, Ergänzung S. 349; Ursula Peters, Literatur in der Stadt. Studien zu den sozialen Voraussetzungen und kulturellen Organisationsformen städtischer Literatur im 13. und 14. Jahrhundert (Studien und Texte zur Sozialgeschichte der Literatur 7). Tübingen 1983, S. 138-168; Gisela Kornrumpf, Michael de Leone. In: Die deutsche Literatur des Mittelalters. Verfasserlexikon. 2. Aufl. Bd. 6 (1987), Sp. 491-503; Bertelsmeier-Kierst (Anm. 36); Frank Fürbeth, Wissensorganisierende Komposithandschriften. Materiale Indizien eines spätmittelalterlichen Handschriftentyps am Beispiel des sog. ,Hausbuchs‘ von Michael de Leone. In: Martin Schubert (Hg.), Materialität in der Editionswissenschaft (Beihefte zu Editio 32). Berlin 2010, S. 293 - 308.

38 Vgl. zur Überlieferung Berndt Jäger, Durch reimen gute lere geben. Untersuchungen zu Überlieferung und Rezeption Freidanks im Spätmittelalter (Göppinger Arbeiten zur Germanistik 238), Göppingen 1978, zum „Hausbuch“ des Michael de Leone besonders S. 25, 79 f., 193 f.; Franz-Josef Holznagel, Der Wiener Codex 2705. Untersuchungen zu Überlieferung und Form kleinerer mittelhochdeutscher Reimpaardichtungen des 13. Jahrhunderts. Habil. masch. Köln 1999. 


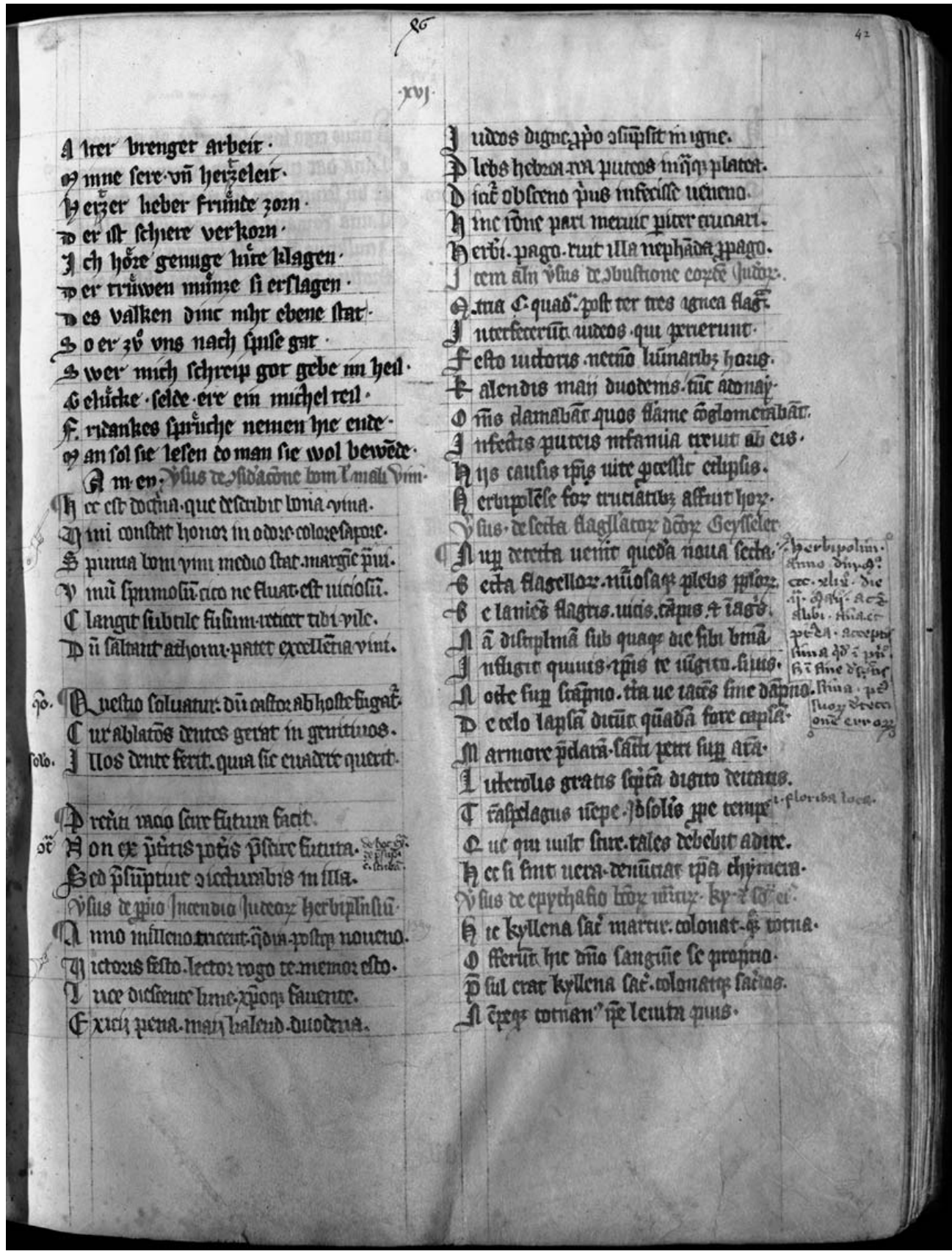

Abb. 13: Schluss von Freidanks ,Bescheidenheit‘ und Nachträge, Hausbuch des Michael de Leone, München, Universitätsbibliothek, $2^{\circ}$ Cod. ms. 731, Bl. 42r - Universitätsbibliothek, München 
Der Schluss des Textes im „Hausbuch“ (B1. 42ra; vgl. Abb. 13) zeigt, dass die Sprüche der ,Bescheidenheit" von mitunter recht schlichter Natur sind. So heißt es am Beginn der linken Spalte etwa: Alter brenget arbeit - Minne sere vnd her[t]zeleit (,Alter bringt Mühsal, Minne Schmerz und Herzeleid“) oder Her[t]zer lieber früde zorn · Der ist schiere verkorn („ein heftiger Streit zwischen guten Freunden ist bald wieder vergessen“). Der Texteintrag von Freidanks ,Bescheidenheit' schließt wenige Zeilen danach mit einem Verspaar, das den Verfasser Freidank und seine sprüche ausdrücklich nennt (Z. 11). ${ }^{39}$

Auf dem darunter befindlichen, ursprünglich freien Platz sind lateinische Hexameter nachgetragen, die ihrerseits auf zeitgenössische Ereignisse aus der Lebenszeit des Michael de Leone Bezug nehmen. Fassbar werden darin die Gefahr einer Pestepidemie im Jahr 1349 sowie die dadurch ausgelösten Judenpogrome und Geißlerzüge. Wie die zwischen einzelnen Versgruppen stehenden Überschriften erkennen lassen, handeln die Verse von der Verbrennung der Würzburger Juden (de proprio Incendio Judeorum Herbipolensium, Bl. 42ra, Z. 26; de combustione eorundem Judeorum, Bl.42rb, Z.6) und von einer secta flagellantorum, die zu deutsch Geysseler genannt werde (B1. 42rb, Z. 15).

Der historische Kontext dieser Angaben lässt sich wie folgt rekonstruieren: ${ }^{40}$ Die sich in Europa seit 1348 verbreitende Pest wurde rasch mit dem fabulösen Vorwurf erklärt, jüdische Mitbewohner hätten in den Städten und Gemeinwesen die Brunnen vergiftet. Zugleich löste die Angst vor der Pest Züge der Geißler aus, die mit rituellen Selbstzüchtigungen über Land zogen, zur Buße aufriefen und dabei große Scharen von Anhängern gewannen. Im April 1349 lastete auf der Stadt Würzburg der Druck sozialer Spannungen. Klerus und Volk waren mit einem päpstlichen Interdikt belegt, seit das Würzburger Domkapitel im Jahr 1345 mit Albrecht von Hohenlohe einen Bischof gewählt hatte, der Papst Clemens VI. nicht genehm war. Hinzu kamen eine verheerende Frostkatastrophe in den Weingärten, die schwere wirtschaftliche Einbußen befürchten ließ, sowie die grassierende Pestangst und der erwähnte Giftvorwurf. Vor diesem Hintergrund spielte sich in der Nacht vom 20. auf den 21. April ein schweres Pogrom ab. Zu den Gewalttätigkeiten, die zur Vernichtung der jüdischen Gemeinde führten, kam es, obwohl die Stadt Würzburg die Juden erst 1337 unter

39 Mit Ausnahme von Superskripten sind graphische Besonderheiten wie Schaft-s hier und in den folgenden Zitaten vereinheitlicht; Abkürzungen werden aufgelöst; nachträgliche Ergänzungen stehen in eckigen Klammern.

40 Vgl. zum Folgenden allgemein: František Graus, Pest - Geißler - Judenmorde. Das 14. Jahrhundert als Krisenzeit (Veröffentlichungen des Max-Planck-Instituts für Geschichte 86). 2., durchges. Aufl. Göttingen 1988. Zu den Geschehnissen in Würzburg: Moszek Awigdor Szulwas, Die Juden in Würzburg während des Mittelalters. Diss. phil. Friedrich-Wilhelms-Universität Berlin 1934, bes. S. 47-50; Hermann Hoffmann, Die Würzburger Judenverfolgung von 1349. Mainfränkisches Jahrbuch für Geschichte und Kunst 5 (1953), S. 91 - 114; Stuart Jenks, Judenverschuldung und Verfolgung von Juden im 14. Jahrhundert: Franken bis 1349. Vierteljahrschrift für Sozial- und Wirtschaftsgeschichte 65 (1978), S. 309-356; Roland Flade, Die Würzburger Juden. Ihre Geschichte vom Mittelalter bis zur Gegenwart. Mit einem Beitrag von Ursula Gehring-Münzel. Würzburg 1987, S. 26-36; Klaus Arnold, Pest - Geißler - Judenmorde. Das Beispiel Würzburg. In: Dieter Rödel u. Joachim Schneider (Hgg.), Strukturen der Gesellschaft im Mittelalter. Interdisziplinäre Mediävistik in Würzburg. Wiesbaden 1996, S. 358-369; HansPeter Baum, Die Vernichtung der jüdischen Gemeinde in Würzburg 1349. In: Ebd., S. 370 -384 (mit weiterer Literatur S. 370 f., Anm. 5); Winfried Romberg, Die religiösen Strömungen im spätmittelalterlichen Würzburg. In: Brunner (Anm. 36), S. 371-389, hier S. 383-385. Speziell zur Dokumentation im ,Hausbuch': Stuart Jenks, The Black Death and Würzburg. Michael de Leone's Reaction in Context. Diss. phil. Yale University 1976, bes. S. 58-145, 216-219; Peters (Anm. 37), S. 150-152. 
einen besonderen Schutz gestellt hatte. Nur etwa zwei Wochen später zog dann eine aus dem thüringischen Raum kommende Geißlerprozession mit heischenden Gesängen in die Stadt ein. Die Kirche, so auch die zu jener Zeit in Acht stehende Würzburger Diözese, stand dieser Laienbewegung sehr skeptisch gegenüber. Am 20. Oktober 1349 wurden die Prozessionen in einer Bulle des Papstes Clemens VI. verboten. Ein Zusammenhang zwischen den massenwirksamen Bußakten der Geißlerzüge und den Judenpogromen kann nicht ausgeschlossen werden, lässt sich aber für die Würzburger Ereignisse des Frühjahrs 1349 nicht objektiv nachweisen. Beide Vorgänge sind vielmehr als Folgeerscheinungen der Pest anzusehen, die, so will es die Ironie der Geschichte, im Jahr 1349 an Würzburg vorüber ging und die Stadt erst 1356 erreichte.

Die im Anhang von Freidanks ,Bescheidenheit‘ auf B1. 42ra/b befindlichen Einträge nehmen auf die Würzburger Ereignisse Bezug. Nach der Art von Merkversen führen die leoninischen (Binnenreim aufweisenden) Hexameter das genaue Datum der Judenverfolgung an, sie nennen den Giftvorwurf und betonen, dass sich die Juden im eigenen Feuer - proprio in igne - selbst verbrannt hätten. ${ }^{41}$ Bei dieser Behauptung, die auch in einem chronikalischen Text des ,Hausbuchs' wiederkehrt, ${ }^{42}$ dürfte es sich um eine verzerrte Wiedergabe der tatsächlichen Vorgänge handeln. Der Ausdruck combustio in der Überschrift der folgenden Versgruppe (Bl. 42rb, Z. 6) und die den cruciatibus („Hinrichtungen“, Z. 14) gewidmeten Bemerkungen am Ende desselben Abschnitts deuten dies an; zudem gibt es Anhaltspunkte dafür, dass Pogrome in der zeitgenössischen Chronistik als Selbstverbrennungen dargestellt wurden. ${ }^{43}$ Vermutlich griff auch Michael de Leone zu dieser Erklärung, um den Leumund seiner Stadt und Diözese nicht noch weiter zu gefährden. Die päpstliche Kurie selbst hatte noch im September 1348 ein Dekretale erlassen, das Gewalttätigkeiten gegen die Juden unter die Strafe der Exkommunikation stellte; hinzu kam die von der Stadt selbst im Jahr 1337 zugesicherte Schutzleistung. ${ }^{44}$ Gegen beide Beschlüsse verstieß das Pogrom vom April 1349 massiv.

Von Parteilichkeit sind auch jene Verse auf B1. 42rb geprägt, die den Geißlerzug beschreiben (Z. 15-27). Der Zug der Flagellanten wird als große Menschenansammlung geschildert, deren Angehörige sich in exzessiven Bußübungen Wunden im Übermaß beibringen (numerosaque plebs populorum. - Se laniens flagris. uicis. campis. et in agris): „Denen schließ dich an, wenn du willst“ (te iungito. si uis.), heißt es in hämischer Anspielung auf ein deutschsprachiges Geißlerlied, das mit dem Ruf $N u$ tret her zü der bo̊ssen welle die Massen anzulocken

41 Vgl. auch die mitunter zu verbessernde Transkription bei Jenks, The Black Death (Anm. 40), S. 220 (die Reimwörter im ersten Vers von Bl. 42rb lauten korrekt digne - igne), sowie Baum (Anm. 40), S. 378.

42 So in einem De occisionibus perfidorum Judeorum überschriebenen Abschnitt der auf B1. 262v-268v eingetragenen Chronik (hier mit der Jahresangabe 1348): Judei Herbipolenses suas domos ibidem de mane incenderunt ac seipsos et sua conbusserunt in eis. (Bl. 266r/v). Vgl. die unter Anm. 40 genannten Arbeiten von Hoffmann, S. 107; Jenks, The Black Death, S. 78; Baum, S. 376.

43 Vgl. die unter Anm. 40 genannten Arbeiten von Graus, S. 260; Jenks, The Black Death, S. 78-82; Baum, bes. S. $377 \mathrm{f}$.

44 Vgl. die unter Anm. 40 genannten Arbeiten von Graus, S. 160; Hoffmann, S. 91 f.; Jenks, The Black Death, S. 81; Baum, S. 379. Das päpstliche Dekretale ist abgedruckt in: Clément VI (1342-1352). Lettres closes, patentes et curiales se rapportant à la France. Publiées ou analysées d'après les registres du Vatican. Hrsg. v. Eugène Déprez, Jean Glénisson u. Guillaume Mollat (Bibliothèque des Écoles françaises d'Athènes et de Rome, Série 3, 3). Bd. 2. Paris 1960, Nr. 3966, S. 491 f. 
suchte. ${ }^{45}$ Von den Geißlern, die nachts auf dem blanken Erdboden schlafen, wird außerdem mitgeteilt, dass sie die Ankunft einer göttlichen Botschaft erwarten. ${ }^{46}$ Die Reserviertheit des Chronisten wird im Schlussvers deutlich: ,so behauptet es, wenn es denn wahr ist, diese ungeheuerliche Sekte“ (Hec si sint uera. denunciat ipsa chymera.). ${ }^{47}$

Die Tatsache, dass Michael de Leone die Verse in sein ,Hausbuch“ aufnimmt, verdeutlicht, dass dieser hier als Kleriker ganz auf den kirchlichen Standpunkt einschwenkt und den Häresieverdacht gegenüber den Geißlern, der wenige Monate später zum päpstlichen Verbot führt, teilt. Eine Marginalie am rechten Rand der Textspalte bestätigt diesen Eindruck. Darin wird nicht nur der Zeitpunkt des Einzugs in Würzburg (2. Mai 1349) genannt, sondern auch die Tatsache, dass die Sekte zunächst auf große Resonanz traf, dann aber wegen ihrer offenkundigen Irrlehren in die Isolation geriet (acceptissima quidem in principio, sed in fine desertissima propter suorum detectionem errorum) ${ }^{48}$

Deutlich manifestiert sich hier die Verketzerung aus kirchlicher Perspektive. Die Marginalie, selbst ein textliches Randphänomen, liefert ein eindrucksvolles Beispiel für die Dynamik sozialer Vorgänge, hier anhand der vorläufigen Integration in die städtische Gemeinschaft und des darauf folgenden Ausschlusses durch das kirchliche Verbot.

Insgesamt geben die in das ,Hausbuch“ des Michael de Leone aufgenommenen Verse ein gleichermaßen irritierendes wie fesselndes Zeugnis mittelalterlicher Marginalisierung ab. Auf beklemmende Weise dokumentieren sie die unter dem Eindruck einer bedrohenden Pestepidemie stehenden Ereignisse in einer mittelalterlichen Bischofsstadt. Aus einer durch lokale und überregionale Konstellationen bedingten Parteinahme heraus bewerten sie die Vorgänge mit kurzen, einprägsamen Angaben - beschreiben dabei, wie einzelne gesellschaftliche Gruppen an den Rand eines Gemeinwesens geraten, ja von diesem regelrecht in die Vernichtung getrieben werden. Im Anhang von Freidanks ,Bescheidenheit' eingetragen, führen die Verse diesen didaktischen Text unvermittelt in die Aktualität eines verstörenden Zeitgeschehens über. Die Randnotizen, so scheint es, machen den vorgängigen Text erst in dessen Grenzen erkennbar, ergreifen von diesem Besitz. An den Rändern der Diskurse von Lehrhaftigkeit und Tagesaktualität ergeben sich Reibungsflächen, die sich vor den Augen der Leser abspielen. ${ }^{49}$

45 Vgl. Arthur Hübner, Die deutschen Geißlerlieder. Studien zum geistlichen Volksliede des Mittelalters. Berlin, Leipzig 1931, S. $106 \mathrm{f}$. - Zu den Bußpraktiken der Geißler James Glass Bertram, Flagellation and the Flagellants. A history of the rod in all countries from the earliest period to the present time. London 1910 (ND als: The History of the Rod. Flagellation and the flagellants in all countries, from the earliest period to the present time [The Kegan Paul library of sexual life]. London 2002), bes. S. 104-109; Niklaus Largier, Lob der Peitsche. Eine Kulturgeschichte der Erregung. München 2001, bes. S. $83-143$.

46 Nocte super scampno terraue iacens sine dampno. - De celo lapsam dicunt quandam fore capsam. Marmore preclaram. sancti petri super aram. - Litterolis gratis scriptam digito deitatis.

47 Die zitierten Verse sind auch transkribiert bei Jenks, The Black Death (Anm. 40), S. 221; vgl. ferner dort S. $132 \mathrm{f}$. Zu weiteren Texten im ,Hausbuch“ des Michael de Leone (Bl. 266va-268rb) vgl. ebd., S. 117 124, 133-145, Transkription S. 221 f., und Stuart Jenks, Die Prophezeiung der Ps.-Hildegard von Bingen: Eine vernachlässigte Quelle über die Geißlerzüge von 1348/49 im Lichte des Kampfes der Würzburger Kirche gegen die Flagellanten. Mainfränkisches Jahrbuch für Geschichte und Kunst 29 (1977), S. $9-38$.

48 Anders als Jenks, The Black Death (Anm. 40), S. 221, Anm. 1, lese ich acceptissima (nicht: acceptos summa), quidem (nicht: quaedam), principio (nicht: presento), desertissima (nicht: derisima).

49 Die Bewegungen sozialer und textlich-diskursiver Marginalisierungsvorgänge sowie deren Interaktionen (nicht nur) in mittelalterlichen Zusammenhängen zu erforschen, wäre zweifellos eine lohnende Aufgabe. Vgl. vorab (jeweils in Auswahl) aus sozialgeschichtlicher Perspektive: Bronislaw Geremek, Les margi- 
Eine diskursive Vernetzung von Texten zeigt sich im ,Hausbuch“ des Michael de Leone auch dergestalt, dass der Redaktor an einzelnen Stellen der Sammelhandschrift der bedrohlichen Pest mit unterschiedlichen Erklärungen und Sprechweisen begegnet. So wird das epidemische Aufkommen der Krankheit nicht nur mit dem erwähnten Giftvorwurf begründet, sondern auch als medizinisches Problem angesehen. Dies geschieht im Rahmen eines Gesundheitstraktats, der die Gefahr eines plötzlichen Tods (subitanea mors) unter anderem auf verseuchte Luft (ex aere corrupto) zurückführt (Bl. 216vb, Z. 1). Eine Randnotiz bezieht diese allgemein gehaltene Diagnose auf die Pest: Nota de pestilentia lautet der entsprechende Vermerk. ${ }^{50}$

Das Beispiel zeigt, wie ein ursprünglich theologischer Begriff in einen medizinischen Kontext gestellt und schließlich auf die Pesterkrankung bezogen wird: Die mors subitanea, von der hier die Rede ist, bezeichnet in der mittelalterlichen Theologie den jähen Tod, der den Sterbenden bei unterlassener Beichte und fehlenden Sterbesakramenten in die ewige Verdammnis führt. ${ }^{51}$ In dem erwähnten Gesundheitstraktat wird dieser Begriff dagegen medizinisch auf den körperlichen Vorgang eines plötzlichen Ablebens bezogen. Erst die Randnotiz benennt schließlich den jähen Tod als Symptom der Pestepidemie.

An einer weiteren Stelle der Handschrift begegnet die volkssprachige Entsprechung des Ausdrucks mors subitanea. Dies geschieht im Zusammenhang mit Gebeten und Beschwörungen, die fur den schelmen des gehen todes, d.h. gegen die Pestseuche und den durch sie verursachten jähen Tod, gesprochen werden sollen (Bl. $7 \mathrm{va}, \mathrm{Z} .1 \mathrm{f}$.) ${ }^{52}$

naux parisiens aux XIVe et XVe siècles. Traduit du polonais par Daniel Beauvois. Paris 1976; Bernhard Kirchgässner u. Fritz Reuter, Städtische Randgruppen und Minderheiten. 23. Arbeitstagung in Worms 16.-18. November 1984 (Stadt in der Geschichte 13). Sigmaringen 1986; Frank Rexroth, Mediävistische Randgruppenforschung in Deutschland. In: Michael Borgolte (Hg.), Mittelalterforschung nach der Wende 1989 (Historische Zeitschrift. Beihefte NF 20). München 1995, S. 427-451; Michael Goodich (Hg.), Other Middle Ages. Witnesses at the Margins of Medieval Society (The Middle Ages Series). Philadelphia 1998; Frank Rexroth, Das Milieu der Nacht. Obrigkeit und Randgruppen im spätmittelalterlichen London (Veröffentlichungen des Max-Planck-Instituts für Geschichte 153). Göttingen 1999; Nilda Guglielmi, Il Medioevo degli ultimi. Emarginazione e marginalità nei secoli XI-XIV (I volti della storia 8). Rom 2001; Bernd-Ulrich Hergemöller (Hg.), Randgruppen der spätmittelalterlichen Gesellschaft. Neu bearb. Ausg. Warendorf 2001; Peter Johanek (Hg.), Die Stadt und ihr Rand (Städteforschung A 70). Köln 2008; ferner David Byrne, Social exclusion (Issues in society). 2. Aufl. Maidenhead 2005. Aus textwissenschaftlich-diskursgeschichtlicher Perspektive: Seth Lerer (Hg.), Reading from the Margins. Textual Studies, Chaucer, and Medieval Literature. San Marino (Calif.) 1996 (zugleich Huntington Library Quarterly 58 [1996], Heft 1); David C. Greetham (Hg.), The Margins of the Text (Editorial Theory and Literary Criticism). Ann Arbor 2000; Sarah Larratt Keefer u. Rolf H. Bremmer Jr (Hgg.), Signs on the Edge. Space, Text and Margin in Medieval Manuscripts (Mediaevalia Groningana new series 10). Paris, Leuven, Dudley MA 2007. Zu bildlichen Randphänomenen Camille (Anm. 30). Kritisch zu berücksichtigen wäre auch das mit einem vage bleibenden (metaphorischen) Textbegriff operierende Marginalismus-Konzept von Heinz Robert Schlette, Der Marginalismus ist ein Humanismus. Nachdruck in: Klaus-Peter Pfeiffer in Verbindung mit Nikolaus Klein u. a. (Hgg.), Vom Rande her? Zur Idee des Marginalismus. Festschrift für Heinz Robert Schlette zum 65. Geburtstag. Würzburg 1996, S. 303-314 (vgl. z. B. S. 303: „Es geht um einen Ort, der als Randposition einem Text zugehört oder korrespondiert;“ ferner die von Schlettes Ansatz ausgehenden Beiträge mit philosophischen, theologischen, ästhetischen und historischen Fragestellungen in der erwähnten Festschrift).

50 Vgl. Jenks, The Black Death (Anm. 40), S. 190.

51 Vgl. Hubert Herkommer, Die alteuropäische Ars moriendi (Kunst des Sterbens) als Herausforderung für unseren Umgang mit Sterben und Tod. Praxis. Schweizerische Rundschau für Medizin 90 (2001), Nr. 49, S. 2144-2151, hier S. 2146.

52 Vgl. Jenks, The Black Death (Anm. 40), S. 207, 213, Transkription S. 222-224. 
Wie sich aus den Textbefunden ergibt, begegnen und überlagern sich im ,Hausbuch ' des Michael de Leone verschiedene Aussageverfahren: Als Erklärung der Pest werden nicht nur soziale Phänomene (wie die vermeintliche Brunnenvergiftung) herangezogen, es bestehen auch Versuche, die Krankheit unter medizinischen Gesichtspunkten zu fassen und ihr durch Gebete beizukommen. Diese Überschneidung lässt ein in der Textredaktion angelegtes Verfahren erkennen, das sich an den Rändern der Diskurse abspielt: Gesellschaftliche, medizinische, theologische und gebetshafte Sprechweisen treten in der Handschrift in ein dialogisches Verhältnis, mittels dessen der Redaktor die Bedrohung durch die Pest zu bewältigen sucht.

\section{Grenzen der Lektüre}

Nach diesem Blick auf die Randbezirke eines sozialen und diskursiven Feldes soll abschließend ein genuin literarisches Randphänomen zur Sprache kommen. Bei dem beispielhaft ausgewählten Manuskript handelt es sich um eine Handschrift aus der Mitte des 13. Jahrhunderts, in der Werke des Dichters Wolfram von Eschenbach aufgezeichnet sind: der Gralroman ,Parzival', die sogenannten ,Titurel'-Bruchstücke und einige wenige Liedtexte (München, Bayerische Staatsbibliothek, Cgm 19). Im vorliegenden Zusammenhang interessiert der vom Autor unvollendet in zwei Fragmentteilen hinterlassene ,Titurel'. Dieser Text ist am Schluss der Handschrift, nach dem ,Parzival', auf einigen verbleibenden Blättern aufgezeichnet (B1. 71r-74r). ${ }^{53}$

Die Benennung ,Titurel' rührt von dem greisen Stammvater der Gralsippe her, dessen Name im ersten Vers der strophischen Dichtung fällt. ${ }^{54}$ Doch anders als dieser Eingang vermuten lässt, handelt der Text von einem jugendlichen Paar an der Schwelle zum Erwachsenenalter. Mitgeteilt wird die Geschichte von Sigune, selbst Angehörige der Gralfamilie, und von Schionatulander, zwei Nebenfiguren aus der großen ,Parzival'-Dich-

53 Vgl. zur Handschrift: Die Münchener Wolfram-Handschrift Cgm 19. DVD mit einem Begleitheft. Konzept und Einführung von Michael Stolz. Simbach a. Inn 2008, und dort den einleitenden Beitrag von Michael Stolz, Die Münchener Wolfram-Handschrift Cgm 19 - Profile einer volkssprachigen Autorhandschrift des 13. Jahrhunderts, S. 1-71. Einschlägige Forschungsliteratur in Auswahl: Karin Schneider, Gotische Schriften in deutscher Sprache, I. Vom späten 12. Jahrhundert bis um 1300. Text- und Tafelband. Wiesbaden 1987, Textband S. 150-154; Thomas Klein, Die Parzivalhandschrift Cgm 19 und ihr Umkreis. In: Joachim Heinzle, L. Peter Johnson u. Gisela Vollmann-Profe (Hgg.), Probleme der Parzival-Philologie. Marburger Kolloquium 1990 (Wolfram-Studien 12). Berlin 1992, S. 32-66; Elisabeth Klemm, Die illuminierten Handschriften des 13. Jahrhunderts deutscher Herkunft in der Bayerischen Staatsbibliothek. Text- und Tafelband (Katalog der illuminierten Handschriften der Bayerischen Staatsbibliothek in München 4). Wiesbaden 1998, Textband S. 217-219, Tafelband [S. 6], Abb. VI, u. S. 186 f., Abb. 558 f.; Martin Baisch, Textkritik als Problem der Kulturwissenschaft. Tristan-Lektüren (Trends in Medieval Philology 9). Berlin, New York 2006, S. 100-115, 123-131, 133-145 u. ö. - Neben dem Münchener Cgm 19 (Hs. G in der Wolfram-Philologie) existieren nur zwei weitere Textzeugen des ,Titurel': die Handschriften München, Universitätsbibliothek, $8^{\circ}$ Cod. ms. 154 (Cim. 80b), Fragment II (um 1300; Hs. M), und Wien, Nationalbibliothek, Cod. ser. nova 2663 (1504-1515/16; Ambraser Heldenbuch, Hs. H). Dazu grundlegend Joachim Bumke, Zur Überlieferung von Wolframs ,Titurel‘. Wolframs Dichtung und der ,Jüngere Titurel'. Zeitschrift für deutsches Altertum und deutsche Literatur 100 (1971), S. 390-431, und ders., Titurelüberlieferung und Titurelforschung. Vorüberlegungen zu einer neuen Ausgabe von Wolframs Titurelfragmenten. Zeitschrift für deutsches Altertum und deutsche Literatur 102 (1973), S. 147-188.

54 Die Gewohnheit, einen Text nach der ersten darin auftretenden Figur zu betiteln, ist im Mittelalter verbreitet; vgl. Joachim Heinzle, Stellenkommentar zu Wolframs ,Titurel'. Beiträge zum Verständnis des überlieferten Textes (Hermaea NF 30). Tübingen 1972, S. 2. 
tung. ${ }^{55}$ Was der Dichter in diesem Versroman nur andeutet, wird in den Strophen des ,Ti-

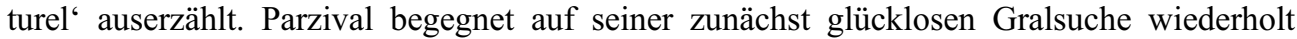
seiner Cousine Sigune, die ihrem Vetter hilft, sich in der undurchsichtigen Gralwelt zu orientieren. Doch während Parzival in den Phasen, die zwischen diesen Begegnungen liegen, allmählich in seine Rolle als künftiger Gralkönig hineinwächst, geht seine Verwandte stufenweise dem leiblichen Verfall entgegen: Sie trauert um ihren im Zweikampf gefallenen Geliebten, den sie gleich einer Mater dolorosa umfangen hält, dem sie später ein Grab bereitet und schließlich in den Tod nachfolgt. ${ }^{56}$

In seinem um 1217/20 verfassten Spätwerk ,Titurel' reicht Wolfram die Vorgeschichte dieser in den ,Parzival' episodenhaft eingelagerten Erzählung nach. ${ }^{57}$ Ein solches Verfahren ist in der volkssprachigen Literatur der Zeit singulär: Der Autor liefert die frei erfundene Vorgeschichte zu einer Erzählung, die er bei seinem Publikum als bekannt voraussetzt. Obwohl die Handlung des ,Parzival' nach jener des ,Titurel' spielt, wird der ,Parzival ‘ damit zur Vorlage für das Verständnis des ,Titurel'. An den Rändern der ,Parzival'-Handlung angesiedelt, greift der ,Titurel` Themen seines epischen Vorwurfs auf, gestaltet diese in Anspielungen und Korrespondenzen, in einem metaphernreichen, an lyrische Formen gemahnenden Stil aus, und lenkt damit wieder auf das epische Zentrum des ,Parzival' zurück. Der späte Text überspielt dabei eine Grenze, die er selbst erst schafft. ${ }^{58}$

Das erste Fragment handelt davon, wie zwischen den beiden noch kindhaften Liebenden die Minne aufkeimt. In Minnegeständnissen vertrauen sie sich den Eltern des noch ungeborenen Parzival an: Sigune erklärt sich Parzivals Mutter Herzeloyde, Schionatulander dessen Vater Gahmuret.

55 Vgl. Wolfram von Eschenbach, Parzival. Nach der Ausgabe Karl Lachmanns rev. u. komm. von Eberhard Nellmann. Übertragen von Dieter Kühn (Bibliothek des Mittelalters 8 [Bibliothek deutscher Klassiker 110]). 2 Bde. Frankfurt a. M. 1994 (daraus die folgenden Zitate).

56 Vgl. zur Sigune-Figur zuletzt Michael Stolz, Cousine sous le chêne - Sigune sur le tilleul. Réflexions sur la réécriture médiévale. In: Florence Bayard u. Astrid Guillaume (Hgg.), Formes et Difformités médiévales. Hommage à Claude Lecouteux (Traditions et Croyances). Paris 2010, S. 407-419 (mit weiterer Literatur).

57 In den letzten Jahren sind mehrere Neuausgaben des Textes erschienen: Wolfram von Eschenbach, Titurel. Hrsg., übers. und mit einem Kommentar und Materialien versehen v. Helmut Brackert und Stephan Fuchs-Jolie. Berlin 2002; dazu die Studienausgabe: Wolfram von Eschenbach, Titurel. Hrsg., übers. und mit einem Stellenkommentar sowie einer Einführung versehen v. Helmut Brackert und Stephan FuchsJolie. Berlin 2003; ferner: Wolfram von Eschenbach, Titurel. Mit der gesamten Parallelüberlieferung des ,Jüngeren Titurel'. Kritisch hrsg., übersetzt und kommentiert v. Joachim Bumke und Joachim Heinzle. Tübingen 2006 (danach, sofern nicht anders angegeben, die folgenden Zitate). Vgl. zu Wolframs ,Titurel' neben Heinzles Stellenkommentar (Anm. 54): Max Wehrli, Wolframs ,Titurel' (Rheinisch-Westfälische Akademie der Wissenschaften, Vorträge G 194). Opladen 1974; Joachim Heinzle, Nachlese zum ,Titurel'-Kommentar. In: Kurt Gärtner u. Joachim Heinzle (Hgg.), Studien zu Wolfram von Eschenbach. Festschrift für Werner Schröder zum 75. Geburtstag. Tübingen 1989, S. 485-500; Christian Kiening u. Susanne Köbele, Wilde Minne. Metapher und Erzählwelt in Wolframs ,Titurel‘. Beiträge zur Geschichte der deutschen Sprache und Literatur 120 (1998), S. 234-265; Joachim Bumke, Wolfram von Eschenbach. 8., völlig neu bearb. Aufl. (Sammlung Metzler 36). Stuttgart, Weimar 2004, S. 407-425; Walter Haug, Vom ,Tristan` zu Wolframs ,Titurel` oder Die Geburt des Romans aus dem Scheitern am Absoluten, in: Deutsche Vierteljahrsschrift für Literaturwissenschaft und Geistesgeschichte 82 (2008), S. 193204, bes. S. $201-204$.

58 Vgl. Kiening/Köbele (Anm. 57), S. 264. 
Im zweiten Fragment wird von der kostbaren Leine eines Bracken erzählt, den Schionatulander in einem Wald eingefangen hat. ${ }^{59}$ Das Brackenhalsband und die Leine tragen eine aus aufgenähten Edelsteinen zusammengesetzte Zierschrift, in deren Lektüre sich Sigune vertieft. Sie liest den Namen des Bracken, Gardevîaz, zu deutsch: hüete der verte (Str. G 137, v. 4). ${ }^{60}$ Und sie entdeckt Teile einer Liebesgeschichte. Der Bracke, so erschließt sich den Lesern aus Sigunes Lektüre, ist ein Bote, seine Leine ein Liebesbrief, dessen Empfänger der Bracke entlaufen ist. Um weiterlesen zu können, knotet Sigune die Leine auf, dabei reißt sich der Bracke los. Als es Schionatulander misslingt, den Bracken wieder einzufangen, drängt ihn Sigune arglos zu neuer Suche, denn sie will die Erzählung auf der Leine zu Ende lesen. An dieser Stelle bricht das zweite Fragment ab. Aus dem ,Parzival'-Roman erschließt sich, dass Schionatulander auf der Suche nach dem Bracken einem Zweikampf zum Opfer fällt: ein bracken seil gap im den pîn $(141,16)$.

Die erhaltenen Bruchstücke des ,Titurel' lassen unschwer einen selbstreflexiven Zug erkennen: Die höfische Epik, aber auch die Schrift als ihr Medium, die Lektüre als eine ihrer Rezeptionsweisen, werden sich hier selbst zum Thema. Dies ist um so auffälliger, als Wolfram im ,Parzival' gerade die Schriftlosigkeit als Pose des Erzählers inszeniert (ine kan decheinen buochstap, 115, 27; ähnliche Äußerungen im Prolog des ,Willehalm', 2, 19 f.). ${ }^{61}$ Der Text bewegt sich an Grenzen, indem er immer wieder auf den ,Parzival' rekurriert, zugleich aber auch Grenzen der Lektüre und ihrer Verständnismöglichkeiten aufzeigt.

Dieses Verfahren lässt sich am handschriftlichen Wortlaut des Textes besonders gut nachvollziehen, da dieser - anders als die vereindeutigenden Verfahren der Interpunktion moderner Editionen - syntaktische Spielräume, Berührungen und Verschiebungen zulässt. Die Strophe G 147 (vgl. Abb. 14) kommentiert den Namen des auf dem Brackenseil genannten Briefempfängers Ehkunat, der den pseudo-französischen Beinamen de Salvâsch Flôrîen (,,von der wilden Blume“) trägt. Das in der Strophe und in weiteren Textresponsionen stereotyp wiederkehrende Leitwort wilde ${ }^{62}$ soll hier die unbezähmbare Fremdheit der Minne von Ehkunat und seiner Geliebten Clauditte, der Senderin des Briefes, betonen. Die dem Brackenseil eingeschriebene Minnehandlung korrespondiert dabei mit dem Minneverhältnis von Sigune und Schionatulander, die sich ihrerseits in einer Wildnis aufhalten: ${ }^{63}$

59 Vgl. Walter Haug, Lesen oder Lieben? Erzählen in der Erzählung, vom ,Erec ‘ bis zum ,Titurel‘. Beiträge zur Geschichte der deutschen Sprache und Literatur 116 (1994), S. 302-323, bes. S. 302 f., 314 f., $321-$ 323; Helmut Brackert, Sinnspuren. Die Brackenseilinschrift in Wolframs von Eschenbach ,Titurel'. In: Harald Haferland u. Michael Mecklenburg (Hgg.), Erzählungen in Erzählungen. Phänomene der Narration in Mittelalter und Früher Neuzeit (Forschungen zur Geschichte der älteren deutschen Literatur 19). München 1996, S. 155-175; Kiening/Köbele (Anm. 57), S. 250-261.

60 Die Angabe „G“ bezieht sich auf die Sigle des Münchener Cgm 19 in der Wolfram-Philologie.

61 Vgl. Michael Stolz, Ine kan decheinen buochstap. Bedingungen vorneuzeitlichen Schreibens am Beispiel der Überlieferung von Wolframs ,Parzival‘. In: Martin Stingelin, Davide Giuriato u. Sandro Zanetti (Hgg.), Mir ekelt vor diesem tintenklecksenden Säkulum. Schreibszenen im Zeitalter der Manuskripte (Zur Genealogie des Schreibens 1). München 2004, S. 22-53, bes. S. $22-26$ (mit weiterer Literatur).

62 Vgl. Kiening/Köbele (Anm. 57), S. 242 f., 246, 254-256; Brackert/Fuchs-Jolie, Eine Einführung. In: Wolfram von Eschenbach, Titurel (Studienausgabe 2003), S. 3-24, hier S. $18 \mathrm{f}$.

63 Die folgenden Zitate nach der Münchener Handschrift. Graphische Besonderheiten wie Schaft-s sind mit Ausnahme von Superskripten vereinheitlicht; Abkürzungen werden aufgelöst; senkrechte Striche verweisen auf Zeilenumbruch. 


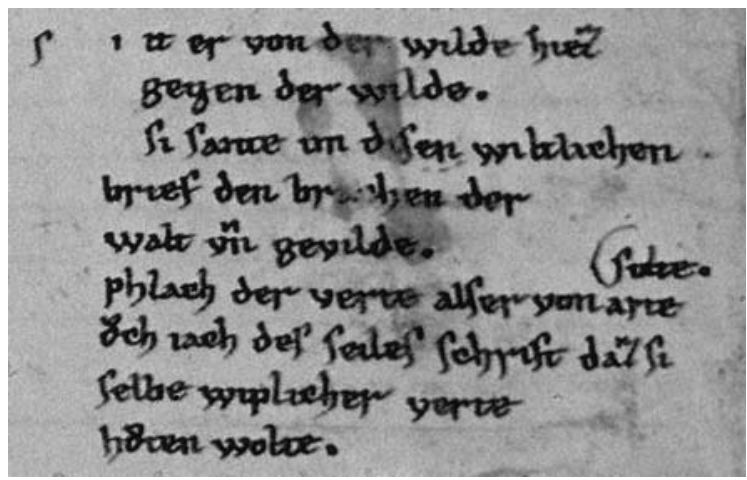

Abb. 14: Strophe G 147 des ,Titurel' Wolframs von Eschenbach, München, Bayerische Staatsbibliothek, Cgm 19, Bl. $73 v c$ - Bayerische Staatsbibliothek, München

sit er von der wilde hiez $\mid$ gegen der wilde.

si sante im disen wiltlichen $\mid$ brief ...

Da er [Ehkunat] nach der Wildnis hieß, sandte sie [Clauditte] ihm in die Wildnis diesen wilden, ungebändigten Brief.

Erst in der fortgesetzten Lektüre erschließt sich die Bedeutung des als wiltlich qualifizierten Briefs, denn dieser wird nun in einer Apposition mit dem Boten gleichgesetzt, dem

brachen der $\mid$ walt vnd gevilde.

phlach der verte alser von arte | solte.

Bracken, der durch Wald und Feld auf der Fährte blieb, wie es seine Art war.

Hier klingt der in einer der vorausliegenden Strophen genannte Name des Bracken an: Gardevîaz - „Gib acht auf die Fährte.“ Der „wilde“ Brief, der Bracke als sein Überbringer, aber auch der Weg, den dieser durch die Wildnis nimmt, sind auf diese Weise durch metonymische Relationen miteinander verknüpft, welche ihrerseits metonymisch auf das sich in derselben Wildnis befindliche Paar Sigune und Schionatulander verweisen. ${ }^{64}$

Im vierten Vers der Strophe wird das in dem Brackennamen zum Ausdruck kommende Programm auf die Senderin des Briefes, Clauditte, bezogen. Dabei deutet der Erzähler zugleich an, wie sich die Schriftzeichen, die auf dem Brackenseil aufgenäht sind, der Leserin Sigune erschließen:

ǒch iach des seiles schrift daz si | selbe wiplicher verte | hovten wolte.

auch besagte die Inschrift des Seils, dass sie selbst auf den Weg, den sie als Frau gehen würde, achten wollte.

64 Eine Phänomenologie metonymischen Erzählens erarbeiten anhand der deutschsprachigen Epik des Mittelalters Harald Haferland u. Armin Schulz, Metonymisches Erzählen. Deutsche Vierteljahrsschrift für Literaturwissenschaft und Geistesgeschichte 84 (2010), S. 3-43. 
Das hüete der verte des Brackennamens kehrt hier als Maxime weiblichen Verhaltens wieder. Die Aussage bleibt dabei eigenartig in der Schwebe zwischen einer Versicherung der Briefschreiberin Clauditte - ,sie wollte auf ihren Weg achten“ - und dem Vorsatz der Leserin Sigune, ihrerseits, dem Beispiel Claudittes folgend, auf ihren Weg achtgeben zu wollen. Wie konsequent Sigune diesem Grundsatz anhängt, bleibt offen: Aus der Perspektive der in den, Titurel'-Fragmenten angelegten Handlung scheitert sie, denn mit ihrem aberwitzigen Wunsch, die Lektüre fortzusetzen, wird sie ihren Geliebten in den Tod treiben. Aus der Perspektive des ,Parzival' ist sie erfolgreich, denn, indem sie den toten Geliebten in unverbrüchlicher Treue betrauert, weist sie zugleich dem Protagonisten des Romans seinen Weg zum Gralkönigtum.

An der betrachteten Strophe wird die Funktion des ,Titurel' als Randphänomen deutlich. Der Text bezieht sich unablässig auf den ,Parzival' und gewinnt gerade aus diesem Bezug seine eigene, selbstreflexive Qualität. Indem er Grenzformen der Lektüre vorführt, oszilliert der ,Titurel' zwischen der in diesem Text erzählten Geschichte und dessen eigenem medialen Status. In Passagen wie dem zuletzt zitierten Vers der Strophe G 147 verunklärt sich, wer Agens der Aussage ist: die Briefschreiberin Clauditte oder die Leserin Sigune. Zugleich aber wird der Status der Lektüre labil: Wer liest? - Sigune selbst oder die im Medium der Schrift über Sigunes Rücken schauenden Leser? ovch iach des seiles schrift - die Schrift behauptet sprechen zu können. Nicht zuletzt im Blick auf die Materialität des handschriftlich überlieferten Textes wird dieser Geltungsanspruch deutlich.

\section{Fazit}

Randgänge der Mediävistik galt es, am Beispiel dreier exemplarischer Themenbereiche zu beschreiten. Anhand ausgewählter Quellenzeugnisse ließ sich eine Zuordnung von Rand und Zentrum erkennen, in der die den mediävistischen Gegenständen eigene Dynamik des „Anderen im Eigenen“ und des „Eigenen im Anderen“ sichtbar wird. So wird in der Struktur der mittelalterlichen Labyrinthe das Bild einer zunächst heillos scheinenden Welt entworfen, die von ihrem Zentrum her erlöst wird. Signum dieser Zuversicht ist das Kreuz, dessen Form sich über die Windungen des Labyrinths lagert und auf Ränder ausgreift, die ihrerseits in das Zentrum zurückweisen. Verwandte Bildkonzepte, wie etwa jene der Weltkarten oder des Bilderzyklus von Zillis, basieren auf einem vergleichbaren Ordnungsprinzip.

Entsprechende Strukturen finden sich aber auch in der Anlage von Texten, besonders deutlich etwa im Layout mittelalterlicher Kommentare, die sich dem Ausgangstext von den Rändern her nähern und dabei eine eigene Dominanz entfalten. Das hier visuell erkennbar werdende Verfahren des Inbesitznehmens eines vorgängigen Textes lie $\beta$ sich auch in graphischen Anlagerungen verfolgen, wie sie etwa im ,Hausbuch“ des Michael de Leone begegnen. Dort gliedern sich Textschichten wie die Merkverse zu Geschehnissen der Pestepidemie einem älteren Text an und dokumentieren dabei gleichermaßen Verfahren einer diskursiven Marginalisierung wie solche einer Vernetzung von Diskursen.

Anhand des zuletzt angeführten Beispiels von Wolframs ,Titurel' schließlich ließ sich zeigen, wie ein Autor von den Rändern eines seiner Werke her ein neues Textgefüge entwirft, das im Bezug auf einen vorgängigen Text den poetischen und medialen Status epischer Dichtung reflektiert. Dabei spielt die von Wolfram inszenierte Erfahrung des Lesens eine nicht unbedeutende Rolle; ansatzweise erschließen sich solche Lektüreprozesse auch 
im Blick auf die Gestalt der mittelalterlichen Manuskripte. In der Münchener WolframHandschrift Cgm 19 ist der ,Titurel` auch mit seiner Positionierung im Textgefüge als Nachtrag zum ,Parzival“ und damit an dessen „Rand“ angesiedelt.

Am Ende der Betrachtungen zu mittelalterlichen Randphänomenen angelangt, scheint es mit der gebotenen Vorsicht angebracht, eine Überzeugung zu äußern: Die Mediävistik selbst ist keine randständige Disziplin; sie darf getrost einen Platz, wenn vielleicht nicht im Zentrum, so doch im vielstimmigen Konzert der wissenschaftlichen Fächer beanspruchen. Ihre mitunter entlegen anmutenden Fragestellungen lassen sich auf zeitlose Konstellationen applizieren und tragen damit mehr zum Verständnis einer komplexen Gegenwart bei, als dies vordergründig den Anschein haben mag.

Prof. Dr. Michael Stolz

Universität Bern

Institut für Germanistik

Länggassstrasse 49

$\mathrm{CH}-3000$ Bern 9

michael.stolz@germ.unibe.ch 